OPEN ACCESS

Edited by:

Xiaona Du,

Hebei Medical University, China

Reviewed by:

Temugin Berta,

University of Cincinnati, United States

Antje Kroner,

Medical College of Wisconsin

United States

*Correspondence:

Ryan L. O'Hare Doig

ryan.doig@sahmri.com

Received: 07 August 2019

Accepted: 24 April 2020

Published: 25 June 2020

Citation:

O'Hare Doig RL, Santhakumar S, Fehily B, Raja S, Solomon T,

Bartlett CA, Fitzgerald $M$ and Hodgetts SI (2020) Acute Cellular and Functional Changes With a

Combinatorial Treatment of Ion Channel Inhibitors Following Spinal

Cord Injury.

Front. Mol. Neurosci. 13:85. doi: 10.3389/fnmol.2020.00085

\section{Acute Cellular and Functional Changes With a Combinatorial Treatment of Ion Channel Inhibitors Following Spinal Cord Injury}

\author{
Ryan L. O'Hare Doig ${ }^{1,2,3,4 *}$, Sreya Santhakumar ${ }^{2,5}$, Brooke Fehily', Sushmitha Raja', \\ Tanya Solomon ${ }^{1}$, Carole A. Bartlett ${ }^{1}$, Melinda Fitzgerald ${ }^{1,5,6}$ and Stuart I. Hodgetts ${ }^{2,5}$ \\ ${ }^{1}$ Experimental and Regenerative Neurosciences, School of Biological Sciences, The University of Western Australia, Crawley, \\ WA, Australia, ${ }^{2}$ Experimental and Regenerative Neurosciences, School of Human Sciences, The University of Western \\ Australia, Crawley, WA, Australia, ${ }^{3}$ Neil Sachse Centre for Spinal Cord Research, South Australian Health and Medical \\ Research Institute, Adelaide, SA, Australia, ${ }^{4}$ Adelaide Spinal Research Group, Faculty of Health and Medical Sciences, The \\ University of Adelaide, Adelaide, SA, Australia, ${ }^{5}$ Perron Institute for Neurological and Translational Science, Nedlands, WA, \\ Australia, ${ }^{6}$ Curtin Health Innovation Research Institute, Curtin University, Nedlands, WA, Australia
}

Reducing the extent of secondary degeneration following spinal cord injury (SCl) is necessary to preserve function, but treatment options have thus far been limited. A combination of the ion channel inhibitors Lomerizine (Lom), YM872 and oxATP, to inhibit voltage-gated $\mathrm{Ca}^{2+}$ channels, $\mathrm{Ca}^{2+}$ permeable AMPA receptors, and purinergic $\mathrm{P} 2 \mathrm{X}_{7}$ receptors respectively, effectively limits secondary consequences of injury in in vitro and in vivo models of CNS injury. Here, we investigated the efficacy of these inhibitors in a clinically relevant model of SCl. Fischer (F344) rats were subjected to a moderate (150 kD) contusive SCl at thoracic level T10 and assessed at 2 weeks or 10 weeks post-injury. Lom was delivered orally twice daily and YM872 and oxATP were delivered via osmotic mini-pump implanted at the time of $\mathrm{SCl}$ until 2 weeks following injury. Open field locomotion analysis revealed that treatment with the three inhibitors in combination improved the rate of functional recovery of the hind limb (compared to controls) as early as 1-day post-injury, with beneficial effects persisting to 14 days post-injury, while all three inhibitors were present. At 2 weeks following combinatorial treatment, the functional improvement was associated with significantly decreased cyst size, increased immunoreactivity of $\beta$-III tubulin ${ }^{+v e}$ axons, myelin basic protein, and reduced lipid peroxidation by-products, and increased $\mathrm{CC} 1^{\text {+ve }}$ oligodendrocytes

\footnotetext{
Abbreviations: AMPA, $\alpha$-amino-3-hydroxy-5-methyl-4-isoxazolepropionic acid; AnkG, ankyrin-G; BBB, Basso, Beattie, and Bresnahan; Ca, calcium; CNS, central nervous system; GAP43, growth-associated protein 43; GFAP, glial fibrillary acidic protein; GluR, glutamate receptor; HNE, 4-hydroxynonenal; K, potassium; MBP, myelin basic protein; Na, sodium; NG2, neural/glial antigen-2; OPC, oligodendrocyte progenitor cell; oxATP, oxidized adenosine triphosphate; P2X, adenosine triphosphate-gated-cation channel family; PDGF $\alpha$, platelet-derived growth factor subunit alpha; SCI, spinal cord injury; SMI-32, anti-neurofilament H non-phosphorylated; VGCC, voltage-gated calcium channel; YM872, [2,3-dioxo-7-(1H-imidazol-1-yl)6-nitro-1,2,3,4-tetrahydro-1-quinoxalinyl] acetic acid monohydrate.
} 
and $\mathrm{NG}^{+\mathrm{ve}} / \mathrm{PDGF} \alpha^{+\mathrm{ve}}$ oligodendrocyte progenitor cell densities, compared to vehicletreated SCl animals. The combination of Lom, OxATP, and YM872 shows preclinical promise for control of secondary degeneration following $\mathrm{SCl}$, and further investigation of long-term sustained treatment is warranted.

Keywords: spinal cord injury, secondary degeneration, ion channel inhibitors, glia, calcium $\left(\mathrm{Ca}^{2+}\right)$, oxidative stress

\section{INTRODUCTION}

Spinal cord injury (SCI) is a seriously debilitating event that can quickly lead to paralysis or even death, with a large physical, emotional, and socioeconomic burden (Ditunno and Formal, 1994). In the United States alone, it is estimated that the annual incidence of SCI injury is 17,000 each year, with approximately 282,000 persons currently living with a SCI (White and Black, 2016). Following SCI, there is an injury severity dependent disruption of axonal pathways (Fehlings and Tator, 1995) impairing motor, sensory and autonomic function at and below the site of injury. Although a significant understanding of the etiology and pathophysiology of SCI has been attained, an effective therapeutic treatment strategy for SCI remains elusive.

When the central nervous system (CNS) is contused, or damaged by a penetrative or compressive force, a plethora of molecular and cellular cascades described as secondary degeneration, exacerbate neurological damage, and functional impairment. The acute phase of secondary degeneration in the CNS can occur minutes to weeks following injury, with the chronic phase appearing from within months to a year (Dihné et al., 2001; Nashmi and Fehlings, 2001; Chen et al., 2003; Fitzgerald et al., 2010; Payne et al., 2012; Petersen et al., 2012). It is understood that the biochemical events associated with secondary degeneration include, but are not limited to glutamate excitotoxicity (Szydlowska and Tymianski, 2010; Tsutsui and Stys, 2013) disruptions of ionic balance of $\mathrm{K}^{+}, \mathrm{Na}^{+}$, and $\mathrm{Ca}^{2+}$ (Choi, 1987; Stys, 2004) free radical formations and lipid peroxidation (Kontos and Wei, 1986; Liu et al., 2004; Vaishnav et al., 2010) with apoptosis of various cell types (Beattie et al., 2000). Specifically, following SCI, damaged neurons release high concentrations of the neurotransmitter glutamate (Park et al., 2004) resulting in $\mathrm{Ca}^{2+}$ dysregulation, compromising cellular machinery (Herrero-Mendez et al., 2009), and increasing cell death (Duchen, 2012) along the apoptotic-necrotic continuum (Cheung et al., 1998).

$\mathrm{Ca}^{2+}$ entry into neurons and glia in the CNS is mediated by several channels, including voltage-gated $\mathrm{Ca}^{2+}$ channels (VGCCs; Sattler et al., 1996; Agrawal et al., 2000) ionotropic $\mathrm{P} 2 \mathrm{X}_{7}$ receptors (Hollmann et al., 1991; North, 2002; Matute et al., 2007) and $\alpha$-amino-3-hydroxy-5-methyl-4-isoxazolepropionic acid (AMPA) receptors lacking the GluR2 subunit (Hollmann et al., 1991). Excessive $\mathrm{Ca}^{2+}$ influx or $\mathrm{Ca}^{2+}$-mediated intracellular $\mathrm{Ca}^{2+}$ release following an injury can activate several $\mathrm{Ca}^{2+}$-dependent processes leading to the overproduction of mitochondrial free radicals, and oxidative damage such as lipid peroxidation (Camello-Almaraz et al., 2006; O'Hare Doig et al., 2014). Lipid peroxidation occurs when reactive oxygen species react with polyunsaturated fatty acids, to form lipid radicals such as 2-propenal (acrolein) and 4-hydroxynonenal (HNE; Hamann and Shi, 2009; Vaishnav et al., 2010) consequently disturbing cellular machineries (Refsgaard et al., 2000). Free radical production and lipid peroxidation following SCI plays an important role in secondary injury (Hall and Braughler, 1982; Barut et al., 1993; Springer et al., 1997; Lewén et al., 2000; Kamencic et al., 2001; Christie et al., 2008).

Neuropathological changes in myelin architecture contribute to deficits in locomotor function following SCI (Guest et al., 2005) Changes seen in myelin structure may reflect disruption in the numbers of oligodendroglia along the differentiation lineage, resulting in perturbed axoglial support (Nave and Trapp, 2008). We have previously demonstrated increased nitrosative and oxidative damage in $\mathrm{CC}^{\text {+ve }}$ mature myelinating oligodendrocytes in vivo following a partial injury to the optic nerve (O'Hare Doig et al., 2014) temporally and spatially associated with changes in the node of Ranvier and paranode axoglial structure (Szymanski et al., 2013). Oligodendrocytes and their progenitors (oligodendrocyte progenitor cells; OPCs) are reported to be particularly vulnerable to oxidative events (Giacci et al., 2018b), initiating necrotic and apoptotic pathways during CNS injury and neurodegenerative disorders such as multiple sclerosis (Bunge et al., 1993; Thorburne and Juurlink, 1996; Juurlink et al., 1998; Gilgun-Sherki et al., 2004; Jana and Pahan, 2007) associated with myelin abnormalities (Payne et al., 2012, 2013; Szymanski et al., 2013; Giacci et al., 2018a) demyelination (Griffiths et al., 1998; Matute et al., 2001; Antony et al., 2004; Norenberg et al., 2004; Doan et al., 2013) and delayed degeneration of axons (Crowe et al., 1997; Warden et al., 2001; Irvine and Blakemore, 2008).

Given the significant effects of excessive $\mathrm{Ca}^{2+}$ influx on cellular structure and function, there has been an increased effort in the use of $\mathrm{Ca}^{2+}$ (or ion) channel inhibitors as a treatment strategy for neurotrauma. Many of these agents such as Lomerizine (Lom), 2,3-dioxo-7-(1H-imidazole-1-yl)6-nitro1,2,3,4-tetrahydro-1-quinoxalinyl acetic acid monohydrate (YM872), and adenosine $5^{\prime}$-triphosphate periodate oxidized sodium salt (oxATP) to inhibit VGCCs, $\mathrm{Ca}^{2+}$ permeable AMPA receptors, and $\mathrm{P}_{2} \mathrm{X}_{7}$ receptors, respectively, have been developed and tested in pre-clinical models and clinical trials of Neurotrauma. Taken together, although promising outcomes have been demonstrated in pre-clinical studies of $\mathrm{Ca}^{2+}$ channel inhibitors, clinical trials utilizing these agents alone for the treatment of neurotrauma alone have been limited and overall disappointing (for review see O’Hare Doig and Fitzgerald, 2015).

To facilitate functional recovery following CNS injury, and in particular SCI, therapeutic strategies must overcome the volatile environment, preserve neuronal and glial cell numbers, and 
limit changes in $\mathrm{Ca}^{2+}$ dynamics, oxidative stress, and myelin abnormalities. It is increasingly recognized that combinatorial treatment strategies are likely to be required to maximize limitation of the multiple detrimental facets of neurotrauma (Tuszynski, 2005; Kelso et al., 2011). Given the complexity of the pathophysiology of CNS trauma, we have previously assessed the efficacy of a variety of combinations of ion channel inhibitors: Lom, YM872, and OxATP both in vitro and in vivo. All three ion channel inhibitors in combination were shown to reduce intracellular $\mathrm{Ca}^{2+}$ concentration, increase cortical cell viability, and preserve astrocytes and neurons following peroxide insult in vitro (O'Hare Doig et al., 2016). Only application of Lom, YM872 and oxATP in combination in vivo up to 3 months following partial injury to the optic nerve limited chronic myelin decompaction and node of Ranvier abnormalities, associated with preservation of optokinetic reflex, indicating preservation of function, in this model; individual inhibitors were less effective (Savigni et al., 2013). Similarly, we have demonstrated the efficacy of this ion channel inhibitor combination in acute partial CNS injury, beneficial outcomes including reduced hyperphosphorylation of tau, acetylated tubulin, and lipid peroxidation; increased Nogo-A immunoreactivity, and preservation of AnkG lengths and OPC numbers (O'Hare Doig et al., 2017). Therefore, it is clear that a combination of ion channel inhibitors targeting different pathways is beneficial in dampening the biochemical sequelae and secondary cascade processes. However, the efficacy of the treatment strategy must be assessed in more clinically relevant models of neurotrauma such as SCI.

Therefore, this study was designed to further assess the efficacy of the ion channel inhibitor combination of Lom, oxATP, and YM872 on key events of secondary degeneration, during the acute and chronic time phases following SCI. The Infinite Horizon impactor device was utilized to provide a clinically relevant, and reproducible moderate thoracic contusion model of SCI in rodents (Anderson and Stokes, 1992), and to mimic the pathophysiology of SCI seen in humans.

\section{MATERIALS AND METHODS}

\section{Animals}

Female Fischer rats (F344; 150-200 g) were bred at the Animal Resources Centre (ARC; Murdoch, WA, Australia), housed under a standard $12 \mathrm{~h}$ light/dark cycle, fed wet and dry rat chow and water ad libitum. All procedures performed complied with the ARRIVE guidelines and were carried out following the "Guide for the Care and Use of Laboratory Animals (National Institutes of Health Publication No. 8023, revised 1978), and were approved by The University of Western Australia's Animal Ethics Committee (AEC, approval number RA/3/100/1405). Animals were of adult age at the time of experimental testing (12-15 weeks old).

\section{Treatments}

Animals $(N=28)$ were randomly allocated into two cohorts: Cohort 1 (2 Weeks; $2 \mathrm{~W}$ ); SCI plus PBS vehicle (2W control; $n=7$ ) or SCI plus ion channel inhibitors ( $2 \mathrm{~W}$ treated; $n=7$ ); Cohort 2
(10 Weeks; 10W), SCI plus PBS vehicle (10W control; $n=7$ ), or SCI plus ion channel inhibitors (10W treated; $n=7)$. Treated animals were administered all three ion channel inhibitors in combination: Lom (LKT Labs, St. Paul, MN, USA), oxATP (Sigma, St. Louis, MO, USA), and YM872 (LKT Labs, St. Paul, MN, USA). The choice of treatment concentrations, length, and timing of delivery was based on previously published studies demonstrating efficacy using these agents individually and demonstration of efficacy in the partial optic nerve transection model (Fitzgerald et al., 2009a,b; Savigni et al., 2013). Therefore, Lom and butter vehicle alone treatments began on the day of surgery, after recovery from anesthesia and continued twice daily for 2 or 10 weeks (cohort dependent). Lom mixed in butter vehicle (30 mg/kg body weight; Tamaki et al., 2003) or butter vehicle alone was administered orally to all animals using a spatula, whilst animals were gently held. OxATP (1 mM; Matute et al., 2007) and YM872 (240 $\mu$ M; Savigni et al., 2013) were delivered directly to the site of injury for the first 2 weeks after injury via an osmotic mini-pump (see below).

\section{Anesthesia and Surgery}

Adult Fisher rats were anesthetized with $2.5 \% \quad(\mathrm{v} / \mathrm{v})$ isoflourothane (BoMac Attane Isoflurane, Hillcrest, Auckland, NZ, USA) combined with $60 \%$ nitrous oxide (v/v) and $38 \%$ oxygen (v/v) for a quick and controlled recovery. A longitudinal incision through the skin and spreading of the underlying muscle tissue was performed, revealing the spinal column. Rats were positioned on a surgical plate for spinal cord impact using flexible armatures and Adson forceps (spinal cord stabilizing forceps). Partial laminectomy at vertebral level T9-T11 exposed the spinal cord underneath without disruption of the meninges. Using an Infinite Horizon impactor device, animals received a moderate T10 contusion (150 kDyne) injury to the dorsal surface of the exposed spinal cord. Following contusion injury, the dura was incised longitudinally, and a pre-filled osmotic mini-pump (Model 2002; $0.5 \mu \mathrm{l} / \mathrm{h}$; ALZET, Cupertino, CA, USA) attached to a brain infusion kit (Kit 3; ALZET, Cupertino, CA, USA) were attached and stabilized via subcutaneous sutures. The vinyl catheter was guided underneath the skin, the brain infusion cannula was placed above the dorsal aspect of the exposed spinal cord, and the 30-gauge stainless steel tube was inserted directly into the injury site. The cannula was sutured in place, muscles were closed in layers and the incision closed with wound clips. Rehydrating saline ( $2 \mathrm{ml}$ subcutaneously) was administered in conjunction with Buprenorphine (Temgesic; $0.01 \mathrm{ml} / 100 \mathrm{~g}$ body weight, [(0.0324 mg/kg body weight), $300 \mathrm{U} / \mathrm{ml}$; Provet, Malaga, WA, Australia] immediately following surgery, and daily until $\sim$ day 5 post-SCI. To prevent wound and bladder infections, Benacillin $[0.02 \mathrm{ml} / 100 \mathrm{~g}$ body weight $(64 \mathrm{mg} / \mathrm{kg}$ body weight), $300 \mathrm{U} / \mathrm{ml}(150 \mathrm{mg} / \mathrm{ml}$ procaine penicillin, $150 \mathrm{mg} / \mathrm{ml}$ benzathine penicillin, $20 \mathrm{mg} / \mathrm{ml}$ procaine hydrochloride); Troy Laboratories Pty. Ltd., Glendenning, NSW, Australia] was administered immediately after and at 2-, 4- and 6-days following surgery. The ALZET brain infusion kits and pumps only remained in situ for 2 weeks following SCI, as previous studies have demonstrated reduced efficiency in delivery, and sometimes, moderate compression damage caused by tubing, at later time 
points (Jones and Tuszynski, 2001; Hodgetts et al., 2013). Therefore, pumps were surgically removed under anesthesia (as described above) at 2 weeks after injury.

\section{Behavioral Analyses-Open Field Recovery (BBB)}

Functional assessments of animals in all experimental groups were performed on days 1-7, then weekly from weeks 2-10 following surgery (cohort dependent) and consisted of open field locomotion assessment. Functional assessment was conducted before surgical removal of osmotic mini-pumps at the 2-week time-point for Cohort 2 animals. Handling and habituation of animals to behavioral apparatus were performed during the week before surgery.

The Basso, Beattie and Bresnahan (BBB) locomotor rating scores were used to assess the range and type of forwarding locomotion (Basso et al., 1995). Briefly, rats were recorded using digital videography in an open field for 2-3 min (per hindlimb) on days $1-7$, and weekly from week $2-10$ post-injury. Recordings were made from a sideways angle, at close range for each hindlimb, as well as views from behind the animals during the test. Scoring of animals ranged from 0 to 21 based on the criteria outline (Basso et al., 1995). At least two independent investigators conducted the assessments, all blinded to experimental group identity. Both scores for each hindlimb were averaged, and the total average score was reported for each animal.

\section{Tissue Preparation}

Following final behavioral tests at 2- or 10-weeks postinjury, animals were euthanized by lethal injection of sodium pentobarbitone (50 mg/100 g; Provet, Malaga, WA, Australia) and transcardially perfused with heparinized PBS, followed by $4 \%(\mathrm{w} / \mathrm{v})$ paraformaldehyde (PFA; Sigma) in $0.1 \mathrm{M}$ phosphate buffer ( $\mathrm{pH}$ 7.2). The vertebral columns were dissected from each animal and postfixed in PFA for $24 \mathrm{~h}$ before cryoprotection in $15 \%(\mathrm{w} / \mathrm{v})$ sucrose in phosphate-buffered saline (PBS; $\mathrm{pH} 7.2)$. A $20 \mathrm{~mm}$ segment was cut from the spinal cord (containing the lesion epicenter and rostral-caudal penumbra), ensuring the injury site was at the midpoint, and embedded in $10 \%$ $(\mathrm{w} / \mathrm{v})$ gelatine (Sigma, St. Louis, MO, USA) in PBS. Gelatine blocks were trimmed and frozen at $-20^{\circ} \mathrm{C}$, then embedded in optimal cutting temperature (OCT) compound (ProSciTech; Kirwan, QLD, Australia) and a cryostat (CM1900, Leica; Wetzlar, Germany) used to cut longitudinal spinal cord sections (35 $\mu \mathrm{m})$. Consecutive series of sections were transferred to 24-well plates containing PBS $+0.1 \%(\mathrm{w} / \mathrm{v})$ sodium azide (Sigma, St. Louis, MO, USA) and stored at $4^{\circ} \mathrm{C}$ until processed for immunohistochemistry (Figure 1).

\section{Cyst Size Analysis}

Quantification of cyst size and tissue sparing was performed by analysis of toluidine blue-stained spinal cord sections. Every seventh longitudinal section of the spinal cord was mounted on slides and air-dried overnight. For all animals, the selected sections were from the same relative location, confirmed by histological analysis. Sections were submerged in $0.05 \%(\mathrm{w} / \mathrm{v})$ toluidine blue [in $0.0055 \%(w / v)$ sodium tetraborate; Sigma,
St. Louis, MO, USA] for $1 \mathrm{~min}$ then rinsed and dehydrated sequentially in $70 \%, 90 \%$ and $100 \%$ (v/v) ethanol for $3 \mathrm{~min}$ each. Slides were then submerged in xylene for $1 \mathrm{~min}$, cover-slipped using DPX slide mounting medium (Sigma, St. Louis, MO, USA), and then stored at room temperature before imaging. Data from each of the stained sections were combined and analyzed to give a total cyst area measurement, and total tissue area measurement, for each animal. The cyst area was defined as the outline of the cyst within the spinal cord section, and tissue area was defined as the outline of the entire spinal cord section within each field of view (FOV), using Fiji image analysis software (Schindelin et al., 2012). The total area of cystic structures was expressed as a percentage of total tissue area per FOV. Whilst there was the possibility of cyst generation caused by catheter placement in the spinal cord parenchyma, the track of the catheter (if any) in spared tissue was visible in sections. As they are typically very thin and distinctly different from the underlying cyst, they were identified (if any) and excluded from the analysis.

\section{Immunohistochemical Assessment}

Selected sections within the lesion epicentre were washed in PBS and immunohistochemical analyses conducted according to established procedures (Fitzgerald et al., 2010; Hodgetts et al., 2013) using primary antibodies recognising: astrocytes, glial fibrillary acid protein (GFAP; 1:1,000; \#ab53554, Abcam, Cambridge, UK); neurons, $\beta$-III-tubulin (1:1,000; MMS-435P-250, Jomar Bioscience, Scoresby, VIC, Australia); non-phosphorylated neurofilaments of mature motor neurons (SMI-32; 1:1,000; \#NE1023, Merck Millipore, Burlington, MA, USA); growth associated protein 43 (GAP43; 1:500; \#SAB4300525, Sigma, St. Louis, MO, USA); myelin basic protein (MBP; 1:500; \#ab40390, Abcam, Cambridge, UK); mature oligodendrocytes (CC1; 1:500; \#ab16794, Merck Millipore, Burlington, MA, USA); oligodendrocyte progenitor cells (OPCs); platelet-derived growth factor alpha (PDGF $\alpha$; 1:500; \#sc-9974, Santa Cruz Biotechnology, Dallas, TX, USA) and neural/glial antigen 2 (NG2; 1:500; \#ab83178, Abcam, Cambridge, UK); lipid peroxidation markers, acrolein (1:500; \#ab37110, Abcam, Cambridge, UK); 4-Hydroxynonenal (HNE; 1:500; \#STA-035, Jomar Bioscience, Scoresby, VIC, Australia), and Hoechst nuclear stain (1:3,000; \#62249, Invitrogen, Carlsbad, CA, USA). Secondary antibodies were species-specific AlexaFluor ${ }^{\circledR} 488$, 555, and 647 (1:400; Life Technologies, Carlsbad, CA, USA) respective for each primary antibody.

\section{Immunohistochemical Analysis and Semi-quantification}

Immunohistochemical labeling was visualized in a single selected section of the spinal cord, in the immediate area surrounding the lesion site for each animal and photographed using either an upright Eclipse E800 microscope (Nikon Corporation, Minato, Tokyo, Japan) or, where co-localization and cellular densities were quantified, a Nikon Eclipse Ti inverted microscope (Nikon Corporation, Minato, Tokyo, Japan). For all outcomes and tissues, images were collected at set constant exposures in a single sitting where possible, and immunointensity analyses were conducted on six $200 \mu \mathrm{m} \times 200 \mu \mathrm{m}$ regions of interest 


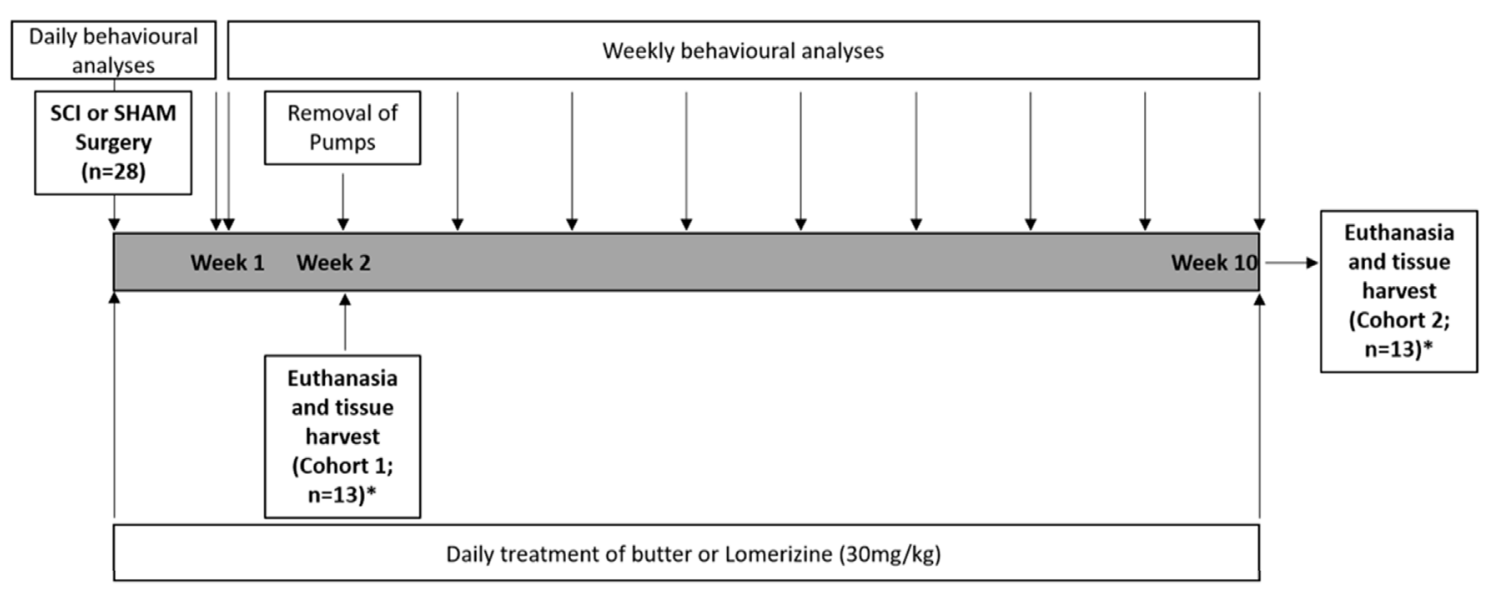

FIGURE 1 | Study design. Following sham or spinal cord injury (SCI) surgery, two cohorts of animals $(N=28)$ were treated daily with butter (orally) or lomerizine (30 mg/kg, orally), and saline or oxATP + YM872 via osmotic mini-pump. Daily behavioral analyses were conducted for the first week following surgery, and then weekly thereafter. Surgical removal of pumps occurred in Cohort 2 animals, only. At 2 weeks (Cohort 1; $n=14$ ) or 10 weeks following surgery (Cohort 2; $n=14$ ), animals were humanely killed and tissue was harvested for analysis. *Total number of animals included in behavioral and histological analysis.

(ROIs; dorsorostral, centrorostral, ventrorostral, dorsocaudal, centrocaudal and ventrocaudal) immediately adjacent to the injury site (Figure 2) using Fiji analysis software (Schindelin et al., 2012). Constant arbitrary threshold intensities for all images for a marker relative to the background (black, no tissue) were set to account for potential variation in section thickness and antibody application, and mean intensities and areas above-set threshold were semi-quantified. As normalization to the background is not possible for oxidative stress data, as oxidized proteins and DNA are diffusely distributed throughout individual cells and or tissue, data relative to other proteins was not normalized. Note that pilot analyses comparing outcomes between the six ROI for analyzed tissue sections within each experimental group did not reveal differences and so data for the six ROI for each tissue section (i.e., animal) were averaged and these means used for further statistical interpretation. Only the mean intensity above threshold rather than the area of immunointensities above the threshold is shown in the following results unless stated within the text. Cell-type-specific densities were quantified through a series of optical images at six individual ROIs at $1 \mu \mathrm{m}$ increments along the $\mathrm{z}$-axis, acquired from the middle $9 \mu \mathrm{m}$ of each cord section. All images were taken in areas surrounding the injury site, where no evidence of cystic structures was present. This ensured any observable changes in immunopositive areas and cell population densities were not due to physical disturbances of spinal cord tissue. Secondary antibody-only controls were processed concurrently to ensure the selectivity of staining (data not shown).

\section{Statistical Analyses}

Mann-Whitney $U$ test for non-parametric data was used to analyze open field locomotion testing (BBB analysis) data, comparing control vs. treated at each time point in separate analyses for the animals euthanized at 2 or 10 weeks. Statistical analyses of cyst size and semi-quantitative immunohistochemical

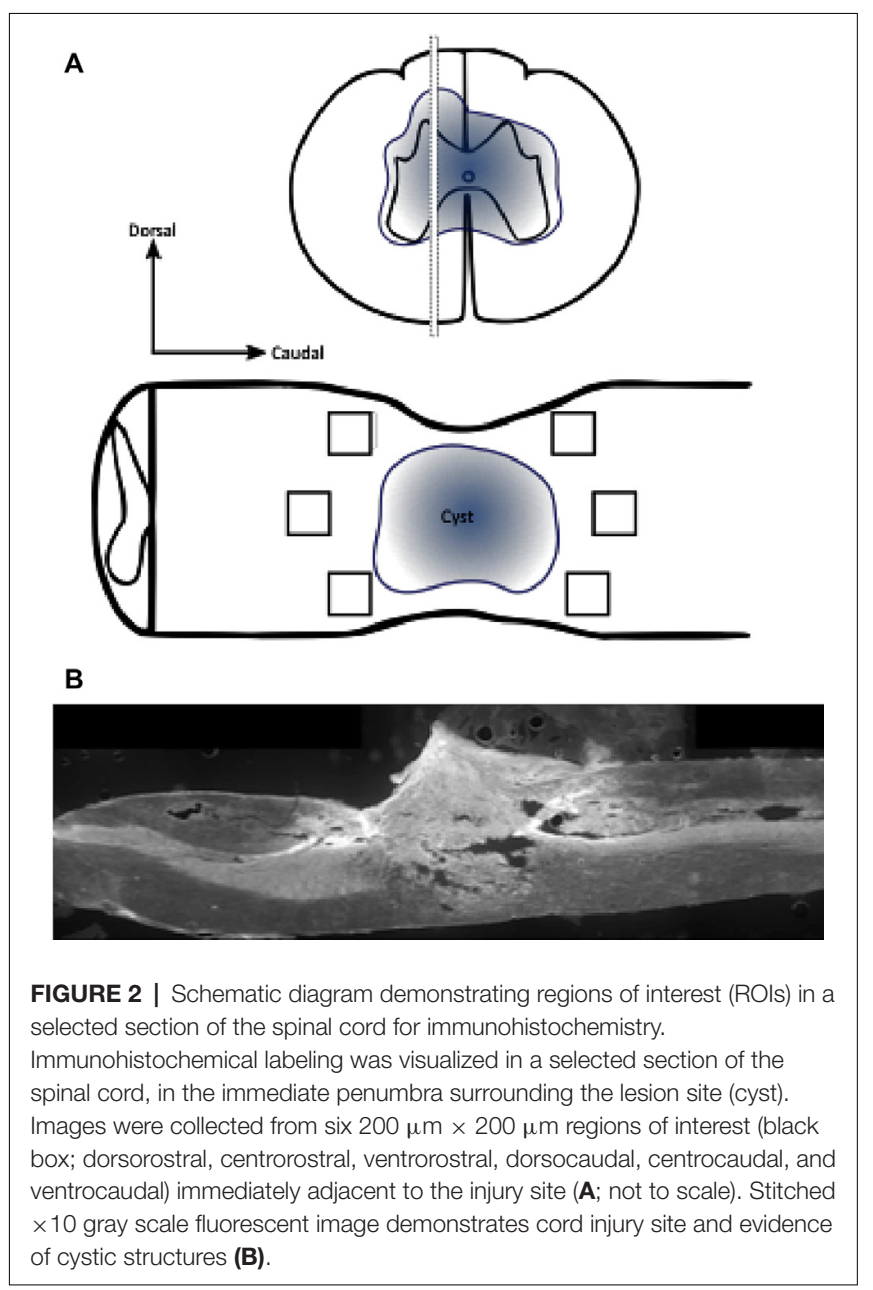

assessments were conducted using a two-way ANOVA followed by Sidak's multiple comparisons test. All statistical analyses 
were performed using GraphPad Prism version 7.00 (GraphPad Software). All data assumes equal variance unless otherwise stated. All data were presented as the mean \pm standard error of the mean. Adjusted $P$ values $\leq 0.05$ were considered statistically significant. For post hoc analyses of cyst size and immunohistochemical assessments, comparisons were made between $2 \mathrm{~W}$ control vs. $2 \mathrm{~W}$ treated, $10 \mathrm{~W}$ control vs. $10 \mathrm{~W}$ treated, $2 \mathrm{~W}$ control vs. $10 \mathrm{~W}$ control, and $2 \mathrm{~W}$ treated vs. $10 \mathrm{~W}$ treated. No sample calculation was performed. The sample size was based on previous research in our laboratory.

\section{RESULTS}

\section{Short Term Combinatorial Ion Channel Inhibitor Treatment Facilitated Significant Early Hindlimb Functional Recovery That Was Not Sustained}

Following injury, animals demonstrated significant locomotor deficits in the hind limbs. Animals demonstrating weight support on the hindlimbs (BBB score $\geq 9$ ) $24 \mathrm{~h}$ following SCI was excluded from both behavioral and histological analysis. These observations typically correlate with an unsuccessful impact of the cord. This only occurred once in each cohort, of the vehicletreated groups. One animal from $2 \mathrm{~W}+$ PBS and 10W + PBS groups were removed from the study analysis. Two cohorts of rats were scored daily for 7 days, and then once weekly thereafter on their ability to generate spontaneous, forward movement, from the day of surgery until endpoint: 14 days (2W: acute) or 70 days (10W: chronic) following SCI. During the 2 weeks of continuous combinatorial administration of ion channel inhibitors, treated animals (of Cohort 1 and 2) demonstrated significant improvement in locomotor function compared to control as early as 1 day and sustained until up to 14 days post-SCI $(p \leq 0.05)$. No significant differences in locomotor movements were observed between control and treated groups from 21 days to 70 days post-SCI (Cohort 2; $p \leq 0.05$; Figure 3; Cohort 2 data shown).

\section{Ion Channel Inhibitor Treatment Reduced Cyst Size and Acute Reactive Gliosis Following SCI}

Cyst formation was calculated as a percentage of the damaged area relative to spared tissue, within each spinal cord segment, 2- and 10-weeks following SCI. Treatment with ion channel inhibitors significantly reduced the cyst area, compared to the relative control groups at $2 \mathrm{~W}\left(F_{(1,22)}=3.126, p=0.0303\right)$. However, there was no significant reduction in cyst size following treatment at $10 \mathrm{~W}\left(F_{(1,22)}=1.73, p=0.462\right)$. Similarly, cyst size did not change across time for either control $\left(F_{(1,22)}=0.153\right.$, $p=0.460)$ or treated animals $(p=0.725$; Figures $4 \mathrm{~A}, \mathrm{~B})$. To determine whether the combination of ion channel inhibitors modified the inhibitory environment surrounding the injury site, the effects of ion channel inhibitors on reactive astrogliosis were assessed. Semi-quantification of GFAP immunoreactivity demonstrated that treated animals at 2 weeks post-SCI had significantly reduced intensity above threshold compared to 2-week controls $\left(F_{(1,22)}=3.677, p=0.009\right)$. However, no effects of treatment were observed between treated and control animals at 10 weeks post-SCI $\left(F_{(1,22)}=0.028, p=0.734\right)$. Although a significant difference was observed between $2 \mathrm{~W}$ control and $10 \mathrm{~W}$ control animals $\left(F_{(1,22)}=4.629, p=0.001\right)$, there was no significant difference between $2 \mathrm{~W}$ treated and $10 \mathrm{~W}$ treated animals $\left(F_{(1,22)}=1.330, p=0.7347\right.$; Figures 4C,D).

\section{Ion Channel Inhibitor Treatment Promoted Changes in $\beta$ III-Tubulin Immunoreactivity, but Not Regenerative Capacity, Within Spared Axons During Acute SCI}

To determine whether the combinatorial ion channel inhibitor therapy preserved axonal integrity and/or promoted axonal sprouting/regeneration following SCI, $\beta$ III-tubulin (Roskams et al., 1998) SMI32 (Carriedo et al., 1996), and GAP43 (Aigner et al., 1995) immunoreactivity were semi-quantified. Following SCI, 2W treated animals had a significant increase in $\beta I I I-$ tubulin intensity above threshold compared to $2 \mathrm{~W}$ controls $\left(F_{(1,22)}=4.279, p=0.002\right)$. This effect was not observed in $10 \mathrm{~W}$ treated animals $\left(F_{(1,22)}=0.292, p>0.999\right)$. Again, there was a significant difference between $2 \mathrm{~W}$ control and $10 \mathrm{~W}$ control animals $\left(F_{(1,22)}=6.277, p<0.001\right)$, however the same difference was not observed between $2 \mathrm{~W}$ treated and $10 \mathrm{~W}$ treated animals $\left(F_{(1,22)}=2.022, p=0.290\right.$; Figures 5A,B). To further determine whether this significant effect was due to sparing of $\beta$ III-tubulin positive axons, the area above threshold, indicative of the number of axons within an area (each ROI), was also analyzed. However, no significant changes were observed between treated or control animals (data not shown). Therefore, it is unlikely that the inhibitors spared axons, but instead there were significant increases in tubulin immunoreactivity within spared axons, perhaps due to conformational alterations. There were no significant differences observed between groups in intensity or area above threshold of SMI32 immunoreactivity at 2W, or $10 \mathrm{~W}$ following SCI $\left(F_{(1,22)}=0.685, p=0.0 .990\right.$; Figures 5C,D $)$. Similarly, there were no significant effects of treatment $\left(F_{(1,22)}=0.300\right.$, $p=0.589)$ or time $\left(F_{(1,22)}=2.596, p=0.121\right)$ between animals in GAP43 immunointensity, $2 \mathrm{~W}$ or $10 \mathrm{~W}$ following SCI, suggesting no effect of injury or treatment on axonal regeneration (Figures 5E,F).

\section{Preservation of MBP Associated With Density Changes in $\mathrm{CC}^{+\mathrm{ve}} / \mathrm{NG}^{-\mathrm{ve}}$ and $\mathrm{NG}^{+\mathrm{ve}} / \mathrm{PDGF} \alpha^{+\mathrm{ve}}$ Oligodendroglia During}

\section{Acute SCI}

To determine the effects of combinatorial ion channel inhibitor therapy on myelin, oligodendrocytes and their progenitors following SCI, MBP immunoreactivity was assessed, and the densities of $\mathrm{CC}^{+\mathrm{ve}} / \mathrm{NG}^{-\mathrm{ve}}$ mature oligodendrocytes and $\mathrm{NG}^{+\mathrm{ve}} / \mathrm{PDGF}^{+\mathrm{ve}} \mathrm{OPCs}$ were quantified. Following treatment, $2 \mathrm{~W}$ animals had no significant changes in MBP immunointensity $\left(F_{(1,22)}=0.66, p=0.987\right.$; Figure 6A), but instead were observed to have a significant increase in MBP immunopositive area above the threshold, when compared to $2 \mathrm{~W}$ control animals 


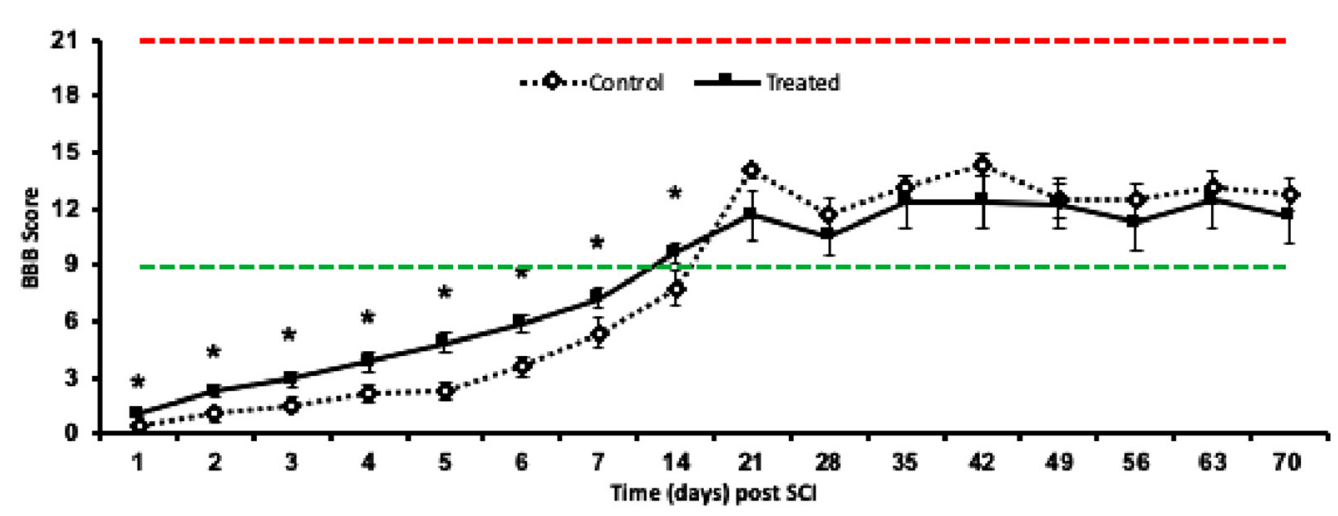

FIGURE 3 | Mean \pm SEM locomotor function assessment (BBB) scores in the open field recovery assessment of hindlimb motor function, up to 10 weeks post-SCI. Animals treated with Lom, OxATP, and YM872 (dashed black line) compared to vehicle-treated control animals (solid black line; ${ }^{*} p \leq 0.05$ ). Red dashed line represents a typical score of completely uninjured, normal animals $(\mathrm{BBB}=21)$ and the green dashed line represents weight supporting $\mathrm{BBB}$ score $(\mathrm{BBB}=9)$. No significant differences were observed between $2 \mathrm{~W}$ and 10W cohorts (data not shown), therefore only 10W cohort shown $(n=6-7 ; n=$ animal numbers).

A

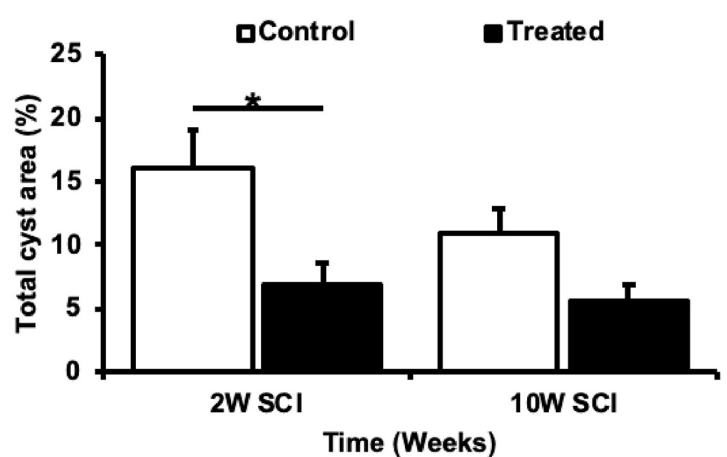

C

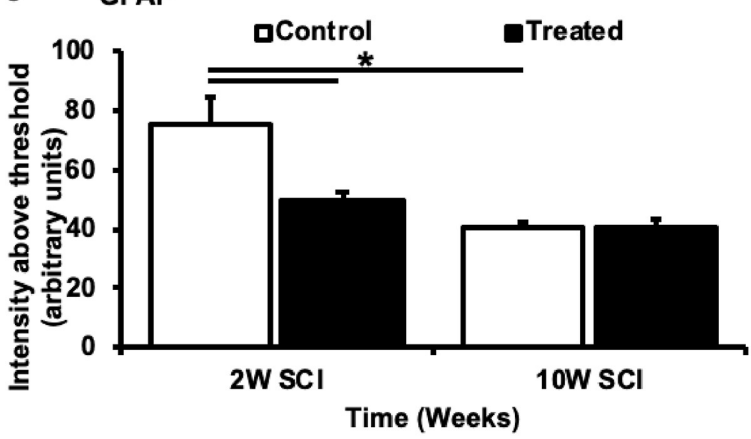

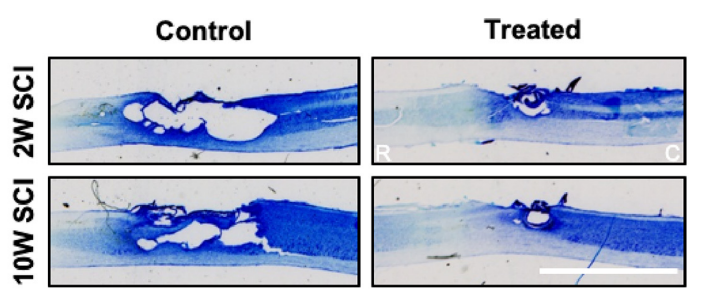

D

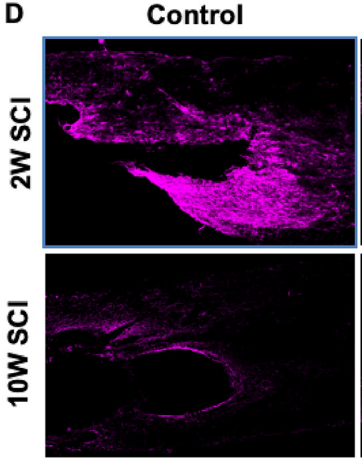

Treated

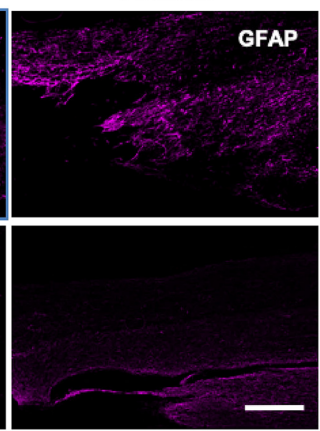

FIGURE 4 | Effects of Lom, oxATP, and YM872 on cyst formation and reactive gliosis of GFAP ${ }^{+v e}$ astrocytes, at 2W and $10 \mathrm{~W}$ post-SCl. (A) Mean \pm SEM of cyst area in toluidine blue-stained spinal cord sections $\left(n=6-7 ;{ }^{*} p \leq 0.05\right)$. (B) Representative images of rostral (R) and caudal (C) regions of a single spinal cord section (scale bar $=5 \mathrm{~mm})$. (C) Mean \pm SEM intensity above the threshold of GFAP immunoreactivity $\left(n=6-7 ;{ }^{*} p \leq 0.05\right)$. (D) Representative images of areas GFAP+ve (magenta) immunoreactivity surrounding the injury site (scale bar $=500 \mu \mathrm{m} ; n=$ animal numbers).

$\left(F_{(1,22)}=3.057, p=0.0036\right.$; Figure 6B). There was an effect of time, with a significant difference observed between the MBP immunointensity observed in $2 \mathrm{~W}$ control and $10 \mathrm{~W}$ treated animals $\left(F_{(1,22)}=4.101, p=0.003\right)$. However, no significant differences in MBP intensity or area above the threshold were observed between $10 \mathrm{~W}$ treated and control animals $\left(F_{(1,22)}=0.013, p<0.999 ;\right.$ Figures 6A-C). Quantification of $\mathrm{CC}^{\text {+ve }} / \mathrm{NG}^{-\mathrm{ve}}$ cells indicated a significant increase in mature oligodendrocyte numbers in treated animals compared to $2 \mathrm{~W}$ controls $\left(F_{(1,22)}=4.879, p<0.001\right)$. However, there 

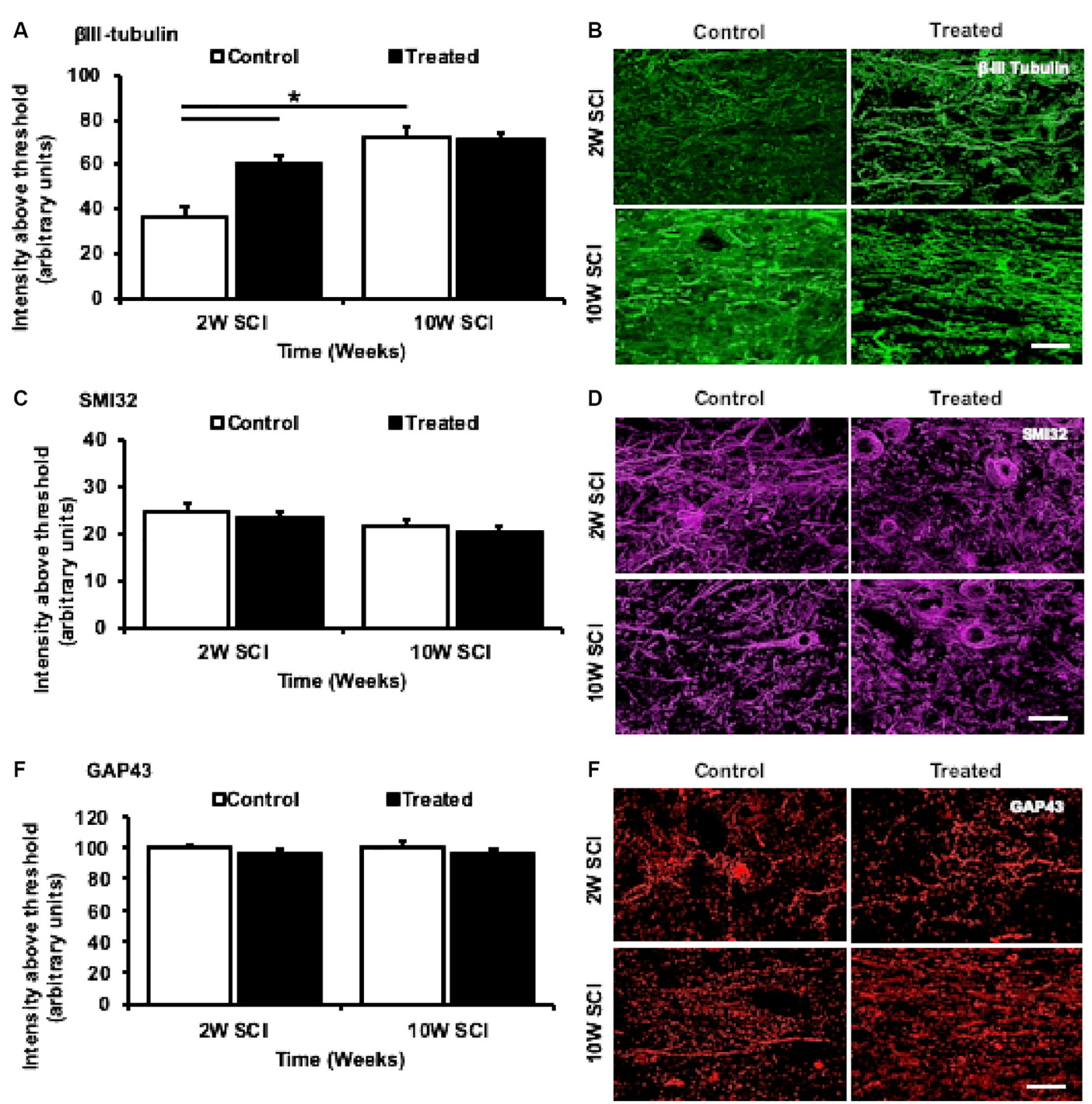

FIGURE 5 | Effects of Lom, oxATP, and YM872 on $\beta$ III-tubulin, SMI32, and GAP43, at 2W and 10W post-SCl. (A-F) Mean \pm SEM of $\beta$ III-tubulin (A), SMI32 (C), and GAP43 (E), immunointensity above threshold $\left(n=6-7{ }^{*}{ }^{*} p \leq 0.05\right)$. Representative images show areas of $\beta$ III-tubulin ${ }^{+v e}$ (green; B), SMI32 ${ }^{+v e}$ (magenta; D) and $\mathrm{GAP}_{4} 3^{+\mathrm{ve}}$ (red; F) immunoreactivity surrounding the injury site (scale bars $=50 \mu \mathrm{m} ; n=$ animal numbers).

were no significant differences between $2 \mathrm{~W}$ and $10 \mathrm{~W}$ control $\left(F_{(1,22)}=2.102, p=0.250\right)$ or $2 \mathrm{~W}$ and $10 \mathrm{~W}$ treated animals $\left(F_{(1,22)}=1.72, p=0.462\right)$, and there were no significant differences in the density of mature oligodendrocytes at $10 \mathrm{~W}$ when comparing treated animals and controls $\left(F_{(1,22)}=0.930\right.$, $p=0$. 9327; Figures 6D,E). Quantification of $\mathrm{NG}^{+\mathrm{ve}} / \mathrm{PDGF} \alpha^{+\mathrm{ve}}$ cells indicated the density of OPCs was significantly increased at $2 \mathrm{~W}$, following treatment with ion channel inhibitors $\left(F_{(1,22)}=5.407, p<0.001\right)$. But, at $10 \mathrm{~W}$ following SCI, the significant effect of treatment was no longer present $\left(F_{(1,22)}=2.67, p=0.085\right)$. Also, there was a significant reduction in OPCs when comparing $10 \mathrm{~W}$ treated to $2 \mathrm{~W}$ treated animals $\left(F_{(1,22)}=6.610 \mathrm{~m} p<0.001\right)$, but no difference between $2 \mathrm{~W}$ and $10 \mathrm{~W}$ controls $\left(F_{(1,22)}=1.891, p=0.366\right.$; Figures 6F,G).

\section{Ion Channel Inhibitor Treatment Limited Lipid Peroxidation During Early SCI}

The effects of combinatorial ion channel inhibitor therapy on oxidative by-products caused by lipid peroxidation were also assessed. Immunohistochemical analysis of lipid peroxidation by-products revealed $2 \mathrm{~W}$ treated animals had significant reductions in both $\operatorname{HNE}\left(F_{(1,22)}=4.090, p=0.0034\right)$ and Acrolein $\left(F_{(1,22)}=3.677, p=0.008\right)$ immunoreactivity compared to $2 \mathrm{~W}$ control animals. Although there was a significant reduction in HNE immunoreactivity with time when comparing $2 \mathrm{~W}$ and $10 \mathrm{~W}$ control animals $\left(F_{(1,22)}=6.134, p<0.001\right)$, there were no significant effects of treatment on $\mathrm{HNE}$ $\left(F_{(1,22)}<0.001, p>0.999\right)$ or Acrolein $\left(F_{(1,22)}=0.003, p>0.999\right)$ immunoreactivity at $10 \mathrm{~W}$ following SCI (Figures 7A-D). 

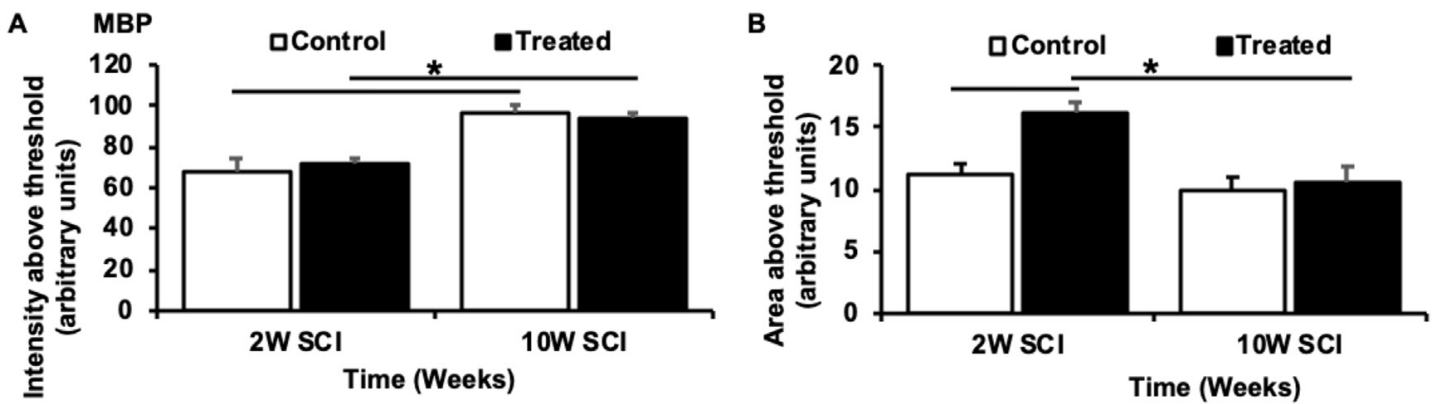

C
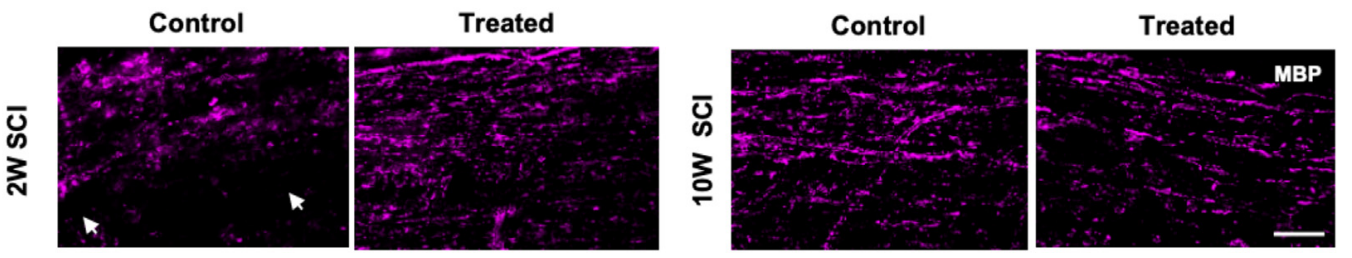

D CC1 $1^{\text {tve }}$ mature oligodendrocytes

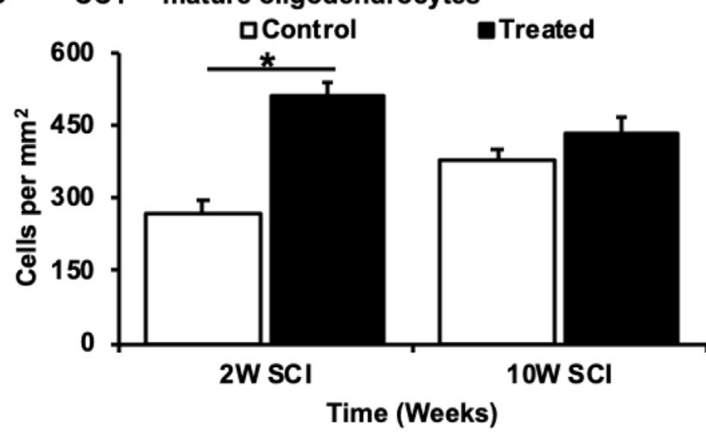

E
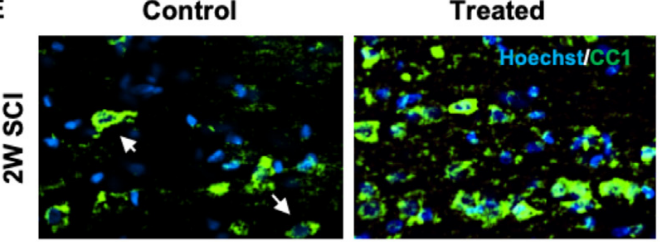

F PDGFa $\alpha^{+v e / N G 2+v e ~ O P C s ~}$
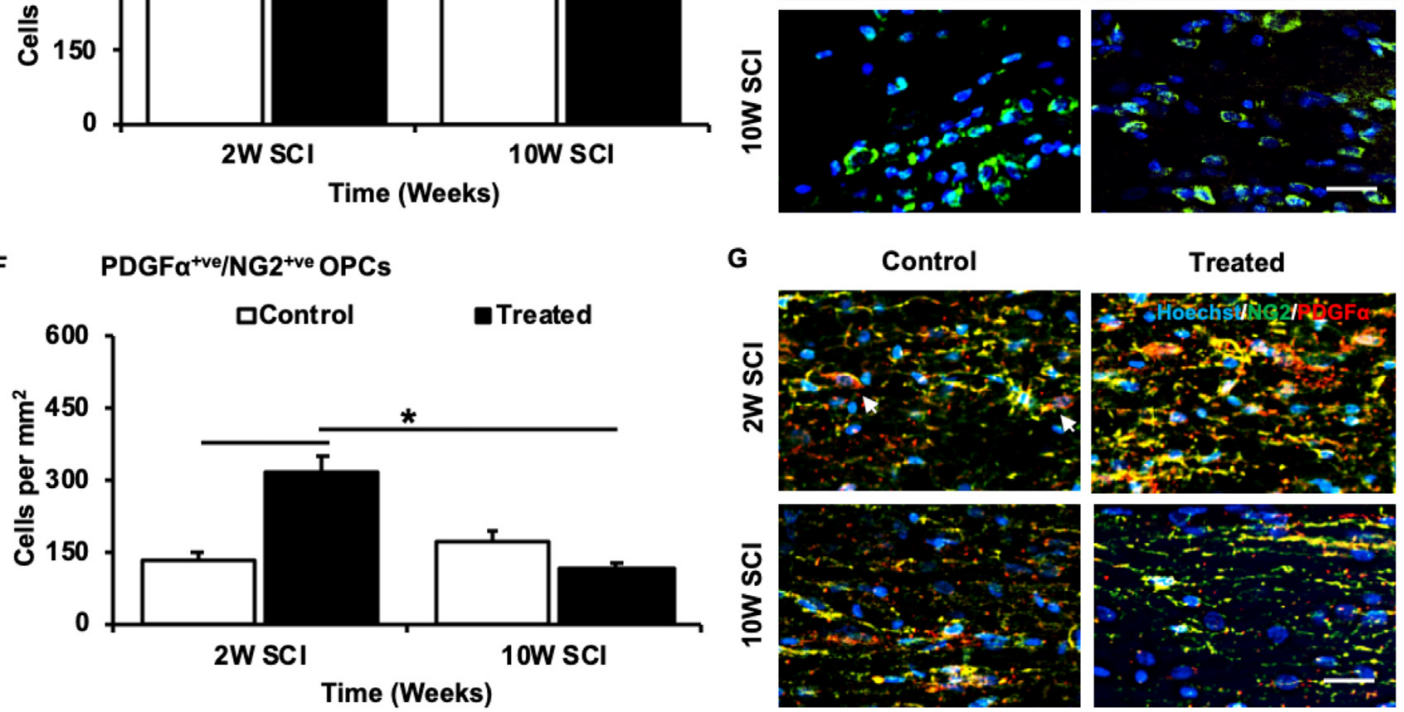

G
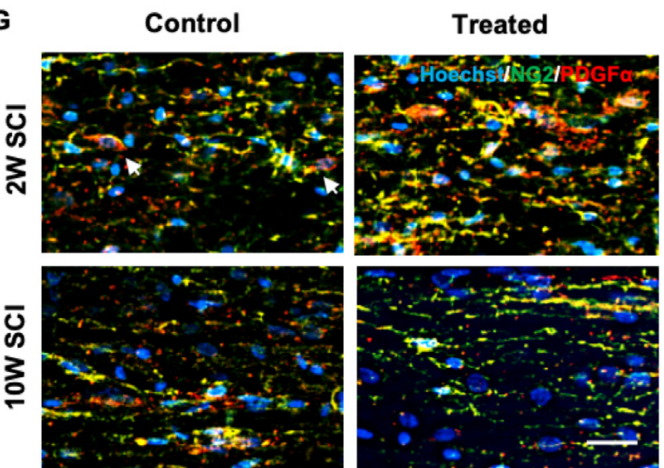

FIGURE 6 | Effects of Lom, oxATP, and YM872 on myelin basic protein (MBP) and oligodendroglia sub-populations, at 2W and 10W post-SCl. (A) Mean \pm SEM intensity above the threshold, and (B) mean \pm SEM area above the threshold of MBP $\left(n=6-7 ;{ }^{*} p \leq 0.05\right)$. (C) Representative images show areas of MBP+ve (magenta) immunoreactivity surrounding the injury site. White arrows demonstrate large area regions where MBP was not detected (scale $=50 \mu \mathrm{m})$. (D) Mean $\pm \mathrm{SEM}$ mature oligodendrocytes cells per $\mathrm{mm}^{2}\left(n=6-7 ;{ }^{*} p \leq 0.05\right)$. (E) Representative images show the density of $\mathrm{CC} 1^{+\mathrm{ve}} \mathrm{NG} 2^{-\mathrm{ve}}$ mature oligodendrocytes (green; indicated by white arrows) surrounding the injury site (scale $=25 \mu \mathrm{m})$. (F) Mean \pm SEM OPCs per mm² $\left(n=6-7 ;{ }^{*} p \leq 0.05\right)$. (G) Representative images show the density of NG2+ve/PDGF $\alpha^{+v e}$ OPCs (green/red; indicated by white arrows) surrounding the injury site (scale $=25 \mu \mathrm{m} ; n=$ animal numbers).

\section{DISCUSSION}

The current study was designed to assess the efficacy of a combination of ion channel inhibitors; Lom, oxATP, and YM872, in a clinically relevant rodent model of the contusion-injured spinal cord. This combination of inhibitors has been previously assessed in well established, high throughput in vitro and in vivo models of acute and chronic CNS injury, 

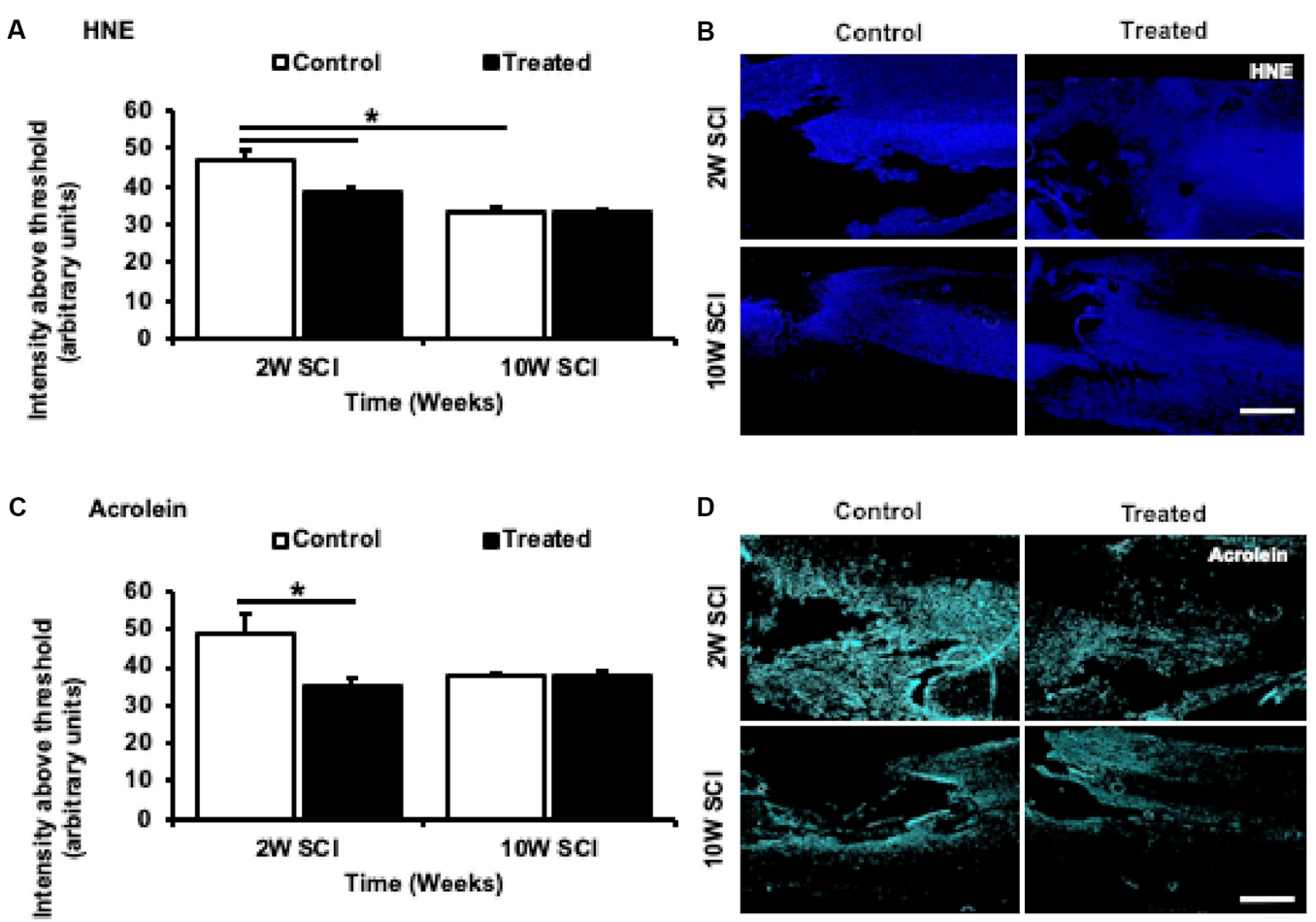

FIGURE 7 | Effects of Lom, oxATP, and YM872 on lipid peroxidation by-products, 4-hydroxynonenal (HNE), and acrolein, at 2W and 10W post-SCl. (A-D) Mean \pm SEM intensity above the threshold of lipid peroxidation by-products 4-hydroxynonenal (HNE) (A) and acrolein (C; $\left.n=6-7 ;{ }^{*} p \leq 0.05\right)$. Representative images show areas of $\mathrm{HNE}^{\text {+ve }}$ (blue; B) and acrolein ${ }^{+v e}$ (cyan; D) immunoreactivity surrounding the injury site (scale bars $=500 \mu \mathrm{m} ; n=$ animal numbers).

consistently demonstrating significant beneficial effects on $\mathrm{Ca}^{2+}$ influx, cell death, oxidative stress, myelin and node of Ranvier changes, as well as visual function (Savigni et al., 2013; O’Hare Doig et al., 2014). This study aimed to assess the effects of the ion channel inhibitor combination on key events of CNS injury, during the acute (2 weeks) and chronic time phases (10 weeks) following SCI. Following treatment with ion channel inhibitors, there was a significant increase in acute functional hindlimb recovery and reduced formation of cystic structures and reactive gliosis surrounding the injury site. These changes were associated with acute increases in $\beta$ III-tubulin and myelin protein immunoreactivity, as well as significant effects on oligodendrocytes and their progenitors, and significant reductions in lipid peroxidation products, acrolein, and HNE. However, all observed effects of treatment (observed acutely) were not seen in chronic SCI animals, once delivery of oxATP and YM872 was removed.

In this study, treatment with Lom, YM872, and oxATP together caused a significant increase in the intensity of $\beta$ IIItubulin $^{+\mathrm{ve}}$ profiles surrounding the injury site, in the thoracic spinal cord. This was associated with reduced formation of cystic structures, as well as improved functional recovery. However, following 10-week treatment, despite an acute reduction of cyst size (increased tissue-sparing), the immunointensity of $\beta$-III tubulin staining, and animal locomotor recovery were no longer significantly different from vehicle control. This suggests the treatment effect is only in the first 2 weeks following SCI when all inhibitors are present. $\beta$-III tubulin is a protein associated with dynamic microtubule extension in neurons (Lee et al., 1990) and although not neuronal-specific, is a useful indicator of re-growing axons (Avwenagha et al., 2003). However, there was no significant increase in GAP43, a marker expressed in elevated levels during development and regeneration, and shown to be up-regulated in growing axons following compressive SCI (Curtis et al., 1993). Thus, it is unlikely that the combination of ion channel inhibitors promoted the regeneration of axons, or altered the endogenous regenerative capacity of these neurons. Instead, the treatment resulted in acute changes in $\beta$ III-tubulin profiles within spared axons, independent of GAP43 upregulation. This may be due to increased (at least temporally) microtubule stabilization, known to reduce scarring and promote axon regeneration after SCI (Hellal et al., 2011). This is plausible, given the increase in $\beta$ III-tubulin profiles and a decrease in cyst area seen in untreated SCI animals, temporally (2W control vs. $10 \mathrm{~W}$ control animals). Interestingly, no significant effects of treatment were observed in SMI32 $2^{\text {ve }}$ profiles (large, mature motor neurons). This may further highlight a selective vulnerability to damage and/or stress of different sub populations of neurons, as shown previously (Morrison et al., 1996; Saroff et al., 2000; Greene et al., 2005; Ren et al., 2005; Wang and Michaelis, 2010). Compared to bipedal primates, quadrupedal mammals typically have a much greater reliance on sensory input from limbs to drive load-bearing spinal locomotor movements. Therefore, 
rodents typically are much more capable of supported hindlimb stepping in the absence of supraspinal input (Côté et al., 2017). Given the final BBB scores of the current study are in the range of 12-14 (chronic animals), we speculate that there is likely little preservation of supraspinal control driving hindlimb functional recovery. As such, final BBB scores are not entirely reflective of the persistent reduction in cyst size (tissue preservation) that was achieved with combinatorial treatment at 2- and 10-weeks post-injury. Inclusion of other functional tests such as the Louisville Swim Scale (Smith et al., 2006) where tactile inputs from fore- and hindlimb are diminished could confirm the extent of supraspinal damage. In conjunction, future studies could combine dye tracing anteroand retrograde dye tracing techniques with an assessment of the density of subpopulations of neurons and their axonal projections, utilizing additional neuronal markers including, but not limited to: calcitonin gene-related peptide to assess sensory neurons (Wiesenfeld-Hallin et al., 1984) and tryptophan, and tyrosine hydroxylase to assess dopaminergic and serotonergic neurons, respectively. Changes in the population of individual subpopulations of cells may reflect specific effects of ion channel inhibitors on particular neuronal subtypes (Van Den Bosch et al., 2000), and may provide greater insight and additional utility for the treatment of SCI. While the effects of the inhibitor combination on axons are not yet fully elucidated, there is a clear association observed between myelin, oligodendrocyte populations, and lipid peroxidation surrounding the injury site.

We have previously demonstrated a host of pathophysiological events that occur during secondary degeneration, including the formation of free radicals, associated with lipid peroxidation (O'Hare Doig et al., 2014). HNE has been shown to rapidly accumulate and consequently inhibit glutamate uptake, following SCI, causing neuronal dysfunction and apoptosis (Springer et al., 1997). Similarly, protein-bound acrolein has also been observed to accumulate, up to 7 days following compressive SCI (Luo et al., 2005). In a recent acute study of partial optic nerve injury, we showed that treatment with Lom, oxATP, and YM872 in combination, reduced various elements of oxidative stress, including lipid peroxidation (O'Hare Doig et al., 2017) associated with preservation of OPCs. In the current study, the acute effects of these inhibitors on by-products of lipid peroxidation were associated with acute changes to MBP immunoreactivity in the injured spinal cord, at 2 weeks, but not 10 weeks following SCI. Similarly, the temporal reduction of $\mathrm{HNE}$ was associated with an increase in myelin profiles seen in non-treated control animals $(2 \mathrm{~W}$ vs. 10W). Oligodendrocytes are known to be vulnerable to oxidative damage following neurotrauma, particularly during proliferative phases and the genesis of myelin sheaths (Juurlink et al., 1998; Roth and Nunez, 2016; Giacci et al., 2018b). ROS, hypochlorous acid, and hydrogen peroxide, along with reactive nitrogen species, hydroxyl radicals and peroxynitrite are likely contributors to the destruction of oligodendroglia following CNS injury (O'Hare Doig et al., 2014). The current study demonstrated a significant increase in the density of OPCs and mature oligodendrocytes following a 2 -week treatment with inhibitors, associated with reduced lipid oxidation. Interestingly, however, at 10 weeks, there was no significant reduction in the number of OPCs observed in treated animals, compared to 10 -week control animals, associated with a lack of change in HNE and Acrolein. It has been established previously that the differentiation of OPCs into mature oligodendrocytes occurs in response to demyelination (Fancy et al., 2004). Therefore, the increased density of OPCs observed in 2 weeks treated animals may be a response to changes in myelin proteins (e.g., MBP), indicated by changes in MBP immunopositive areas. The increased number of $\mathrm{CC}^{\text {+ve }}$ acutely may reflect the early survival of OPCs, which then differentiate into mature oligodendrocytes. Previous studies have demonstrated changes in proliferation and migration of the oligodendrocyte and OPC populations in response to demyelination following SCI (Keirstead et al., 1998; Totoiu and Keirstead, 2005). However, it is as yet unclear whether the observed changes in mature oligodendrocytes are the cause of MBP changes in the present study, in turn driving the accumulation and then differentiation of OPCs (Sim et al., 2002) Alternatively, an acute selective vulnerability of oligodendroglia to oxidative damage may be the underlying cause of myelin changes, and observed density changes of oligodendrocytes, and their progenitors, following SCI treatment (Back et al., 1998, 2001; Giacci et al., 2018b). Specifically, delayed oxidative damage in the sub-population of oligodendroglia may account for the decrease in numbers of OPCs observed in treated animals at 10 weeks following SCI, compared to 2 weeks. However, this interpretation remains a matter of speculation. Therefore, future assessment of myelin status using established electron microscopy measures (i.e., ratio) are warranted.

This is the first study to assess the effects of combined Lom, oxATP, and YM872 treatment in a clinically relevant model of SCI and provides early indications of efficacy of acute treatment. In this initial study, we have demonstrated efficacy with 2 weeks of treatment, however, further work will be needed in future studies to distinguish between the lack of sustained treatment or lack of efficacy to explain the 10-week outcome. Like many injury and disease state models, differences in treatment delivery, anatomy, physiology and relative scale between humans and other mammals leads to difficulties in interpretation. Rodent models of SCI provide a plethora of advantages compared to non-human primate models, with several reproducible methods well described, including established behavioral assessments (for an extensive review see Hodgetts et al., 2009). Several studies have shown the successful treatment of CNS injury using osmotic mini-pumps in rodents. However, many of these studies do not demonstrate efficacy following chronic implantation in the spinal cord, either due to experimental design (only measuring acute time points), complications exacerbated by the implantation of the pump, such as tissue ablation, catheter failure, dislodgment or obstruction, and inconsistent/adverse drug delivery (de Yebenes et al., 1987; Bear et al., 1990; Lu and Hagg, 1997; Angel et al., 1998; Hodgetts et al., 2013). These limitations demonstrate the difficulty of microinfusing blood-brain-barrier impermeable agents which must be given directly to the spinal cord and/or injury site. Despite such 
difficulties, we have demonstrated that the combined delivery of Lom, oxATP, and YM872 is associated with acute beneficial effects following SCI. However, chronic administration of oxATP and/or YM872 is likely needed to further improve the changes, such as functional improvements, seen at 2 weeks. Due to experimental design, we do not know if surgical procedures involving the removal of osmotic mini-pumps administrating these reagents, exacerbated further secondary events following SCI that were not measured in the current study, potentially hindering further functional improvements that may have resulted from the acute treatment. A literature review indicates that the longer-term effects of surgically removing osmotic mini-pumps have not been examined in depth (Jones and Tuszynski, 2001) and need to be explored further. Similarly, future studies should incorporate plasma/serum sampling to ensure the longitudinal functionality of the osmotic mini-pumps and inhibitor stability. Similarly, for clinical use, it will be necessary for future studies to determine how long after injury the combined treatment can be delayed, and efficacy maintained. In our optic nerve transection model, delayed combinatorial treatment by $6 \mathrm{~h}$ resulted in improvements in visual function, and the associated reduction in oxidative stress indicators (Yates et al., 2017). This suggests, time-delayed treatment (clinically relevant to acute SCI) of ion channel inhibitors remains a therapeutically viable option. In contrast, it might be that the ion channel inhibitors slow the rate of tissue loss, but ultimately not the final amount which may be due to impaired blood flow. This could be exploited as a way of buying time at the scene of emergency whilst patients are transported for more definitive treatments (e.g., decompressive surgery), and could be assessed in the acute phase $(\leq 72 \mathrm{~h})$ in pre-clinical studies.

Regardless, the current study was designed to assess the particular combination of inhibitors shown to be efficacious following partial optic nerve transection, in a clinically relevant model of SCI. However, to overcome the difficulties of microinfusion, blood-brain-barrier permeable drug alternatives are worth pursuing. Peng et al. (2009) found that an analog FD\&C blue dye, No. 1, Brilliant Blue G (BBG), can be used to selectively antagonize $\mathrm{P}_{2} \mathrm{X}_{7}$ receptors in vivo, due to its low toxicity (Remy et al., 2008), high selectivity (Jiang et al., 2000) and ability to cross the Bbb (Peng et al., 2009). Administration of BBG reduced cord damage and improved motor recovery, associated with reduced inflammatory and glial activation, and infiltration (Peng et al., 2009). The combination of systemically administered Lom, YM872, and BBG have shown good effects in a rodent model of repeated mild traumatic brain injury and comparable to local delivery at improving outcomes following partial optic nerve transection (Mao et al., 2018; Toomey et al., 2019). Therefore, future studies should assess the effects of systemic delivery of blood-brain-barrier permeable Lom and YM872 (Nishiyama et al., 1999) with BBG, following SCI.

\section{CONCLUSION}

This study provides empirical evidence for the utility of combinatorial ion channel inhibitor treatment regimens to facilitate acute improvements in hindlimb functional recovery, following contusive SCI. We have provided evidence that significant positive changes in early functional recovery and pathophysiology can be achieved acutely with a combinatorial treatment employing Lom, oxATP and YM872 ion channel inhibitors following SCI, including reduced cyst formation and glial reactivity, increased tubulin, reduced demyelination and lipid peroxidation by-products, and changes in mature oligodendrocytes and their progenitors. Very few studies show similar marked improvements in locomotor function at such early time points. Oxidative stress modulation may be beneficial for other acute injury regimes that have shown or show promise, utilizing a combinatorial approach. However, the observed beneficial effects appear to be governed by the method and/or length of delivery of the treatment, highlighting the importance of both an acute therapeutic window and a longitudinal treatment regime. Therefore, future studies should further assess the efficacy of ion channel inhibitor combinations in chronic models of SCI, incorporating therapeutic timing and clinical validity, improved drug delivery mechanisms, bio-activity/availability, and/or blood-brainbarrier permeability properties.

\section{DATA AVAILABILITY STATEMENT}

The datasets generated for this study are available on request to the corresponding author.

\section{ETHICS STATEMENT}

The animal study was reviewed and approved by The University of Western Australia Animal Ethics Committee (RA/3/100/1405).

\section{AUTHOR CONTRIBUTIONS}

RO'H: preparation of the draft manuscript. MF and SH: provided funding and infrastructure support. $\mathrm{RO} \mathrm{H}^{\prime} \mathrm{H}, \mathrm{MF}$ and $\mathrm{SH}$ : idea conception, experimental design, and data interpretation. $\mathrm{RO}^{\prime} \mathrm{H}$, SS, BF, SR, TS, and CB: data collection and analysis.

\section{FUNDING}

We acknowledge financial support from the Neurotrauma Research Program (NRP), Western Australia, National Health and Medical Research Council (NHMRC), Australia (APP1061791), and the Neil Sachse Centre for Spinal Cord Research.

\section{ACKNOWLEDGMENTS}

We thank Ms. Jade Kenna and Ms. Breanna Dixon for assistance with animal handling and initial data analyses, respectively. 


\section{REFERENCES}

Agrawal, S. K., Nashmi, R., and Fehlings, M. G. (2000). Role of L- and N-type calcium channels in the pathophysiology of traumatic spinal cord white matter injury. Neuroscience 99, 179-188. doi: 10.1016/s0306-4522(00) 00165-2

Aigner, L., Arber, S., Kapfhammer, J. P., Laux, T., Schneider, C., Botteri, F., et al. (1995). Overexpression of the neural growth-associated protein GAP-43 induces nerve sprouting in the adult nervous system of transgenic mice. Cell 83, 269-278. doi: 10.1016/0092-8674(95)90168-x

Anderson, T. E., and Stokes, B. T. (1992). Experimental models for spinal cord injury research: physical and physiological considerations. J. Neurotrauma 9, S135-S142. doi: 10.1089/neu.1992.9.113

Angel, I. F., Gould, H. J. Jr., and Carey, M. E. (1998). Intrathecal morphine pump as a treatment option in chronic pain of nonmalignant origin. Surg. Neurol. 49, 92-99. doi: 10.1016/s0090-3019(97)00287-5

Antony, J. M., Van Marle, G., Opii, W., Butterfield, D. A., Mallet, F., Yong, V. W., et al. (2004). Human endogenous retrovirus glycoprotein-mediated induction of redox reactants causes oligodendrocyte death and demyelination. Nat. Neurosci. 7, 1088-1095. doi: 10.1038/nn1319

Avwenagha, O., Campbell, G., and Bird, M. M. (2003). Distribution of GAP-43, $\beta$ III tubulin and $\mathrm{F}$-actin in developing and regenerating axons and their growth cones in vitro, following neurotrophin treatment. J. Neurocytol. 32, 1077-1089. doi: 10.1023/B:NEUR.0000021903.24849.6c

Back, S. A., Gan, X., Li, Y., Rosenberg, P. A., and Volpe, J. J. (1998). Maturation-dependent vulnerability of oligodendrocytes to oxidative stressinduced death caused by glutathione depletion. J. Neurosci. 18, 6241-6253. doi: 10.1523/JNEUROSCI.18-16-06241.1998

Back, S. A., Luo, N. L., Borenstein, N. S., Levine, J. M., Volpe, J. J., and Kinney, H. C. (2001). Late oligodendrocyte progenitors coincide with the developmental window of vulnerability for human perinatal white matter injury. J. Neurosci. 21, 1302-1312. doi: 10.1523/JNEUROSCI.21-04-01302.2001

Barut, S., Canbolat, A., Bilge, T., Aydin, Y., Cokneseli, B., and Kaya, U. (1993). Lipid peroxidation in experimental spinal cord injury: time-level relationship. Neurosurg. Rev. 16, 53-59. doi: 10.1007/bf00308614

Basso, D. M., Beattie, M. S., and Bresnahan, J. C. (1995). A sensitive and reliable locomotor rating scale for open field testing in rats. J. Neurotrauma 12, 1-21. doi: 10.1089/neu.1995.12.1

Bear, M. F., Kleinschmidt, A., Gu, Q., and Singer, W. (1990). Disruption of experience-dependent synaptic modifications in striate cortex by infusion of an NMDA receptor antagonist. J. Neurosci. 10, 909-925. doi: 10.1523/JNEUROSCI.10-03-00909.1990

Beattie, M. S., Farooqui, A. A., and Bresnahan, J. C. (2000). Review of current evidence for apoptosis after spinal cord injury. J. Neurotrauma 17, 915-925. doi: 10.1089/neu.2000.17.915

Bunge, R. P., Puckett, W. R., Becerra, J. L., Marcillo, A., and Quencer, R. M. (1993). Observations on the pathology of human spinal cord injury. A review and classification of 22 new cases with details from a case of chronic cord compression with extensive focal demyelination. Adv. Neurol. 59, 75-89.

Côté, M.-P., Murray, M., and Lemay, M. A. (2017). Rehabilitation strategies after spinal cord injury: inquiry into the mechanisms of success and failure. J. Neurotrauma 34, 1841-1857. doi: 10.1089/neu.2016.4577

Camello-Almaraz, C., Gomez-Pinilla, P. J., Pozo, M. J., and Camello, P. J. (2006). Mitochondrial reactive oxygen species and $\mathrm{Ca}^{2+}$ signaling. Am. J. Physiol. Cell Physiol. 291, C1082-C1088. doi: 10.1152/ajpcell.00217.2006

Carriedo, S. G., Yin, H. Z., and Weiss, J. H. (1996). Motor neurons are selectively vulnerable to AMPA/kainate receptor-mediated injury in vitro. J. Neurosci. 16, 4069-4079. doi: 10.1523/JNEUROSCI.16-13-04069.1996

Chen, S., Pickard, J. D., and Harris, N. G. (2003). Time course of cellular pathology after controlled cortical impact injury. Exp. Neurol. 182, 87-102. doi: 10.1016/s0014-4886(03)00002-5

Cheung, N. S., Pascoe, C. J., Giardina, S. F., John, C. A., and Beart, P. M. (1998). Micromolar L-glutamate induces extensive apoptosis in an apoptoticnecrotic continuum of insult-dependent, excitotoxic injury in cultured cortical neurones. Neuropharmacology 37, 1419-1429. doi: 10.1016/s00283908(98)00123-3

Choi, D. W. (1987). Ionic dependence of glutamate neurotoxicity. J. Neurosci. 7, 369-379. doi: 10.1523/JNEUROSCI.07-02-00369.1987
Christie, S. D., Comeau, B., Myers, T., Sadi, D., Purdy, M., and Mendez, I. (2008). Duration of lipid peroxidation after acute spinal cord injury in rats and the effect of methylprednisolone. Neurosurg. Focus 25:E5. doi: 10.3171/foc.2008. 25.11.e5

Crowe, M. J., Bresnahan, J. C., Shuman, S. L., Masters, J. N., and Crowe, M. S. (1997). Apoptosis and delayed degeneration after spinal cord injury in rats and monkeys. Nat. Med. 3, 73-76. doi: 10.1038/nm0197-73

Curtis, R., Green, D., Lindsay, R. M., and Wilkin, G. P. (1993). Up-regulation of GAP-43 and growth of axons in rat spinal cord after compression injury. J. Neurocytol. 22, 51-64. doi: 10.1007/bf01183975

de Yebenes, J. G., Fahn, S., Mena, M., Pardo, B., and Casarejos, M. (1987). Intracerebroventricular infusion of dopamine and its agonists in rodents and primates. An experimental approach to the treatment of Parkinson's disease. ASAIO Trans. 34, 951-957. doi: 10.1002/mds.870020302

Dihné, M., Block, F., Korr, H., and Töpper, R. (2001). Time course of glial proliferation and glial apoptosis following excitotoxic CNS injury. Brain Res. 902, 178-189. doi: 10.1016/s0006-8993(01)02378-2

Ditunno, J. F. Jr., and Formal, C. S. (1994). Chronic spinal cord injury. N. Engl. J. Med. 330, 550-556. doi: 10.1056/NEJM199402243300808

Doan, V., Kleindienst, A. M., McMahon, E. J., Long, B. R., Matsushima, G. K., and Taylor, L. C. (2013). Abbreviated exposure to cuprizone is sufficient to induce demyelination and oligodendrocyte loss. J. Neurosci. Res. 91, 363-373. doi: $10.1002 /$ jnr.23174

Duchen, M. R. (2012). Mitochondria, calcium-dependent neuronal death and neurodegenerative disease. Pflugers Arch. 464, 111-121. doi: 10.1007/s00424012-1112-0

Fancy, S. P., Zhao, C., and Franklin, R. J. (2004). Increased expression of Nkx2.2 and Olig2 identifies reactive oligodendrocyte progenitor cells responding to demyelination in the adult CNS. Mol. Cell. Neurosci. 27, 247-254. doi: 10.1016/j.men.2004.06.015

Fehlings, M. G., and Tator, C. H. (1995). The relationships among the severity of spinal cord injury, residual neurological function, axon counts, and counts of retrogradely labeled neurons after experimental spinal cord injury. Exp. Neurol. 132, 220-228. doi: 10.1016/0014-4886(95)90027-6

Fitzgerald, M., Bartlett, C. A., Evill, L., Rodger, J., Harvey, A. R., and Dunlop, S. A. (2009a). Secondary degeneration of the optic nerve following partial transection: the benefits of lomerizine. Exp. Neurol. 216, 219-230. doi: 10.1016/j.expneurol.2008.11.026

Fitzgerald, M., Payne, S. C., Bartlett, C. A., Evill, L., Harvey, A. R., and Dunlop, S. A. (2009b). Secondary retinal ganglion cell death and the neuroprotective effects of the calcium channel blocker lomerizine. Invest. Ophthalmol. Vis. Sci. 50, 5456-5462. doi: 10.1167/iovs.09-3717

Fitzgerald, M., Bartlett, C. A., Harvey, A. R., and Dunlop, S. A. (2010). Early events of secondary degeneration after partial optic nerve transection: an immunohistochemical study. J. Neurotrauma 27, 439-452. doi: 10.1089/neu. 2009.1112

Giacci, M. K., Bartlett, C. A., Huynh, M., Kilburn, M. R., Dunlop, S. A., and Fitzgerald, M. (2018a). Three dimensional electron microscopy reveals changing axonal and myelin morphology along normal and partially injured optic nerves. Sci. Rep. 8:3979. doi: 10.1038/s41598-018-22361-2

Giacci, M. K., Bartlett, C. A., Smith, N. M., Iyer, K. S., Toomey, L. M., Jiang, H., et al. (2018b). Oligodendroglia are particularly vulnerable to oxidative damage after neurotrauma in vivo. J. Neurosci. 38, 6491-6504. doi: 10.1523/JNEUROSCI.1898-17.2018

Gilgun-Sherki, Y., Melamed, E., and Offen, D. (2004). The role of oxidative stress in the pathogenesis of multiple sclerosis: the need for effective antioxidant therapy. J. Neurol. 251, 261-268. doi: 10.1007/s00415-004-0348-9

Greene, J. G., Dingledine, R., and Greenamyre, J. T. (2005). Gene expression profiling of rat midbrain dopamine neurons: implications for selective vulnerability in parkinsonism. Neurobiol. Dis. 18, 19-31. doi: 10.1016/j.nbd. 2004.10.003

Griffiths, I., Klugmann, M., Anderson, T., Yool, D., Thomson, C., Schwab, M. H., et al. (1998). Axonal swellings and degeneration in mice lacking the major proteolipid of myelin. Science 280, 1610-1613. doi: 10.1126/science.280.5369. 1610

Guest, J., Hiester, E., and Bunge, R. (2005). Demyelination and Schwann cell responses adjacent to injury epicenter cavities following chronic human spinal cord injury. Exp. Neurol. 192, 384-393. doi: 10.1016/j.expneurol.2004.11.033 
Hall, E. D., and Braughler, J. M. (1982). Effects of intravenous methylprednisolone on spinal cord lipid peroxidation and $\mathrm{Na}^{+}+\mathrm{K}^{+}$)-ATPase activity. Dose-response analysis during 1st hour after contusion injury in the cat. J. Neurosurg. 57, 247-253. doi: 10.3171/jns.1982.57.2.0247

Hamann, K., and Shi, R. (2009). Acrolein scavenging: a potential novel mechanism of attenuating oxidative stress following spinal cord injury. J. Neurochem. 111, 1348-1356. doi: 10.1111/j.1471-4159.2009.06395.x

Hellal, F., Hurtado, A., Ruschel, J., Flynn, K. C., Laskowski, C. J., Umlauf, M., et al. (2011). Microtubule stabilization reduces scarring and causes axon regeneration after spinal cord injury. Science 331, 928-931. doi: 10.1126/science. 1201148

Herrero-Mendez, A., Almeida, A., Fernández, E., Maestre, C., Moncada, S., and Bolaños, J. P. (2009). The bioenergetic and antioxidant status of neurons is controlled by continuous degradation of a key glycolytic enzyme by APC/CCdh1. Nat. Cell Biol. 11, 747-752. doi: 10.1038/ncb1881

Hodgetts, S. I., Plant, G. W., and Harvey, A. R. (2009). Spinal cord injury: experimental animal models and relation to human therapy. J. Chem. Neuroanat. 31, 2-36. doi: 10.1016/b978-0-12-374247-6.50018-3

Hodgetts, S. I., Simmons, P. J., and Plant, G. W. (2013). A comparison of the behavioral and anatomical outcomes in sub-acute and chronic spinal cord injury models following treatment with human mesenchymal precursor cell transplantation and recombinant decorin. Exp. Neurol. 248, 343-359. doi: 10.1016/j.expneurol.2013.06.018

Hollmann, M., Hartley, M., and Heinemann, S. (1991). Ca ${ }^{2+}$ permeability of KAAMPA-gated glutamate receptor channels depends on subunit composition. Science 252, 851-853. doi: 10.1126/science.1709304

Irvine, K. A., and Blakemore, W. F. (2008). Remyelination protects axons from demyelination-associated axon degeneration. Brain 131, 1464-1477. doi: 10.1093/brain/awn080

Jana, A., and Pahan, K. (2007). Oxidative stress kills human primary oligodendrocytes via neutral sphingomyelinase: implications for multiple sclerosis. J. Neuroimmune Pharmacol. 2, 184-193. doi: 10.1007/s11481-0079066-2

Jiang, L. H., Mackenzie, A. B., North, R. A., and Surprenant, A. (2000). Brilliant blue G selectively blocks ATP-gated rat $\mathrm{P}_{2} \mathrm{X}_{7}$ receptors. Mol. Pharmacol. 58, 82-88. doi: 10.1124/mol.58.1.82

Jones, L. L., and Tuszynski, M. H. (2001). Chronic intrathecal infusions after spinal cord injury cause scarring and compression. Microsc. Res. Tech. 54, 317-324. doi: $10.1002 /$ jemt.1144

Juurlink, B. H. J., Thorburne, S. K., and Hertz, L. (1998). Peroxide-scavenging deficit underlies oligodendrocyte susceptibility to oxidative stress. Glia 22, 371-378. doi: 10.1002/(sici)1098-1136(199804)22:4<371::aid-glia6>3.0.co;2-6

Kamencic, H., Griebel, R. W., Lyon, A. W., Paterson, P. G., and Juurlink, B. H. (2001). Promoting glutathione synthesis after spinal cord trauma decreases secondary damage and promotes retention of function. FASEB J. 15, 243-250. doi: 10.1096/fj.00-0228com

Keirstead, H. S., Levine, J. M., and Blakemore, W. F. (1998). Response of the oligodendrocyte progenitor cell population (defined by NG2 labelling) to demyelination of the adult spinal cord. Glia 22, 161-170. doi: 10.1002/(sici)1098-1136(199802)22:2<161::aid-glia7>3.0.co;2-a

Kelso, M. L., Scheff, N. N., Scheff, S. W., and Pauly, J. R. (2011). Melatonin and minocycline for combinatorial therapy to improve functional and histopathological deficits following traumatic brain injury. Neurosci. Lett. 488, 60-64. doi: 10.1016/j.neulet.2010.11.003

Kontos, H. A., and Wei, E. P. (1986). Superoxide production in experimental brain injury. J. Neurosurg. 64, 803-807. doi: 10.3171/jns.1986.64.5.0803

Lee, M. K., Tuttle, J. B., Rebhun, L. I., Cleveland, D. W., and Frankfurter, A. (1990). The expression and posttranslational modification of a neuron-specific $\beta$-tubulin isotype during chick embryogenesis. Cell Motil. Cytoskeleton 17, 118-132. doi: $10.1002 / \mathrm{cm} .970170207$

Lewén, A., Matz, P., and Chan, P. H. (2000). Free radical pathways in CNS injury. J Neurotrauma 17, 871-890. doi: 10.1089/neu.2000.17.871

Liu, D., Liu, J., Sun, D., and Wen, J. (2004). The time course of hydroxyl radical formation following spinal cord injury: the possible role of the iron-catalyzed Haber-Weiss reaction. J. Neurotrauma 21, 805-816. doi: 10.1089/0897715041269650

Lu, X., and Hagg, T. (1997). Glial cell line-derived neurotrophic factor prevents death, but not reductions in tyrosine hydroxylase, of injured nigrostriatal neurons in adult rats. J. Comp. Neurol. 388, 484-494. doi: 10.1002/(sici)10969861(19971124)388:3<484::aid-cne10>3.0.co;2-m

Luo, J., Uchida, K., and Shi, R. (2005). Accumulation of acrolein-protein adducts after traumatic spinal cord injury. Neurochem. Res. 30, 291-295. doi: 10.1007/s11064-005-2602-7

Mao, Y., Black, A. M. B., Milbourn, H. R., Krakonja, S., Nesbit, M., Bartlett, C. A., et al. (2018). The effects of a combination of ion channel inhibitors in female rats following repeated mild traumatic brain injury. Int. J. Mol. Sci. 19:E3408. doi: 10.3390/ijms19113408

Matute, C., Alberdi, E., Domercq, M. A., Pérez-Cerdá, F., Pérez-Samartín, A., and Sánchez-Gómez, M. A. V. (2001). The link between excitotoxic oligodendroglial death and demyelinating diseases. Trends Neurosci. 24, 224-230. doi: 10.1016/s0166-2236(00)01746-x

Matute, C., Torre, I., Pérez-Cerdá, F., Pérez-Samartín, A., Alberdi, E., Etxebarria, E., et al. (2007). P2X $\mathrm{X}_{7}$ receptor blockade prevents ATP excitotoxicity in oligodendrocytes and ameliorates experimental autoimmune encephalomyelitis. J. Neurosci. 27, 9525-9533. doi: 10.1523/JNEUROSCI.057907.2007

Morrison, B. M., Gordon, J. W., Ripps, M. E., and Morrison, J. H. (1996). Quantitative immunocytochemical analysis of the spinal cord in G86R superoxide dismutase transgenic mice: neurochemical correlates of selective vulnerability. J. Comp. Neurol. 373, 619-631. doi: 10.1002/(sici)10969861(19960930)373:4<619::aid-cne9>3.0.co;2-4

Nashmi, R., and Fehlings, M. G. (2001). Changes in axonal physiology and morphology after chronic compressive injury of the rat thoracic spinal cord. Neuroscience 104, 235-251. doi: 10.1016/s0306-4522(01)00009-4

Nave, K. A., and Trapp, B. D. (2008). Axon-glial signaling and the glial support of axon function. Annu. Rev. Neurosci. 31, 535-561. doi: 10.1146/annurev.neuro. 30.051606.094309

Nishiyama, T., Gyermek, L., Lee, C., Kawasaki-Yatsugi, S., and Yamaguchi, T. (1999). The systemically administered competitive AMPA receptor antagonist, YM872, has analgesic effects on thermal or formalin-induced pain in rats. Anesth. Analg. 89, 1534-1537. doi: 10.1097/00000539-199912000-00041

Norenberg, M. D., Smith, J., and Marcillo, A. (2004). The pathology of human spinal cord injury: defining the problems. J. Neurotrauma 21, 429-440. doi: $10.1089 / 089771504323004575$

North, R. A. (2002). Molecular physiology of P2X receptors. Physiol. Rev. 82, 1013-1067. doi: 10.1152/physrev.00015.2002

O’Hare Doig, R. L., Bartlett, C. A., Maghzal, G. J., Lam, M., Archer, M., Stocker, R., et al. (2014). Reactive species and oxidative stress in optic nerve vulnerable to secondary degeneration. Exp. Neurol. 261, 136-146. doi: 10.1016/j.expneurol. 2014.06.007

O’Hare Doig, R. L., Bartlett, C. A., Smith, N. M., Hodgetts, S. I., Dunlop, S. A., Hool, L., et al. (2016). Specific combinations of ion channel inhibitors reduce excessive $\mathrm{Ca}^{2+}$ influx as a consequence of oxidative stress and increase neuronal and glial cell viability in vitro. Neuroscience 339, 450-462. doi: 10.1016/j.neuroscience.2016.10.005

O’Hare Doig, R. L., Chiha, W., Giacci, M. K., Yates, N. J., Bartlett, C. A., Smith, N. M., et al. (2017). Specific ion channels contribute to key elements of pathology during secondary degeneration following neurotrauma. BMC Neurosci. 18:62. doi: 10.1186/s12868-017-0380-1

O'Hare Doig, R. L., and Fitzgerald, M. (2015). Novel combinations of ion channel inhibitors for treatment of neurotrauma. Discov. Med. 19, 41-47.

Park, E., Velumian, A. A., and Fehlings, M. G. (2004). The role of excitotoxicity in secondary mechanisms of spinal cord injury: a review with an emphasis on the implications for white matter degeneration. J. Neurotrauma 21, 754-774. doi: 10.1089/0897715041269641

Payne, S. C., Bartlett, C. A., Harvey, A. R., Dunlop, S. A., and Fitzgerald, M. (2012). Myelin sheath decompaction, axon swelling, and functional loss during chronic secondary degeneration in rat optic nerve. Invest. Ophthalmol. Vis. Sci. 53, 6093-6101. doi: 10.1167/iovs.12-10080

Payne, S. C., Bartlett, C. A., Savigni, D. L., Harvey, A. R., Dunlop, S. A., and Fitzgerald, M. (2013). Early proliferation does not prevent the loss of oligodendrocyte progenitor cells during the chronic phase of secondary degeneration in a CNS white matter tract. PLoS One 8:e65710. doi: 10.1371/journal.pone.0065710

Peng, W., Cotrina, M. L., Han, X., Yu, H., Bekar, L., Blum, L., et al. (2009). Systemic administration of an antagonist of the ATP-sensitive receptor P2X7 improves 
recovery after spinal cord injury. Proc. Natl. Acad. Sci. U S A 106, 12489-12493. doi: 10.1073/pnas.0902531106

Petersen, J. A., Wilm, B. J., von Meyenburg, J., Schubert, M., Seifert, B., Najafi, Y., et al. (2012). Chronic cervical spinal cord injury: DTI correlates with clinical and electrophysiological measures. J. Neurotrauma 29, 1556-1566. doi: 10.1089/neu.2011.2027

Refsgaard, H. H., Tsai, L., and Stadtman, E. R. (2000). Modifications of proteins by polyunsaturated fatty acid peroxidation products. Proc. Natl. Acad. Sci. U S A 97, 611-616. doi: 10.1073/pnas.97.2.611

Remy, M., Thaler, S., Schumann, R. G., May, C. A., Fiedorowicz, M., Schuettauf, F., et al. (2008). An in vivo evaluation of Brilliant Blue $\mathrm{G}$ in animals and humans. Br. J. Ophthalmol. 92, 1142-1147. doi: 10.1136/bjo.2008.138164

Ren, Y., Liu, W., Jiang, H., Jiang, Q., and Feng, J. (2005). Selective vulnerability of dopaminergic neurons to microtubule depolymerization. J. Biol. Chem. 280, 34105-34112. doi: 10.1074/jbc.m503483200

Roskams, A. J. I., Cai, X., and Ronnett, G. V. (1998). Expression of neuron-specific $\beta$-III tubulin during olfactory neurogenesis in the embryonic and adult rat. Neuroscience 83, 191-200. doi: 10.1016/s0306-4522(97)00344-8

Roth, A. D., and Nunez, M. T. (2016). Oligodendrocytes: functioning in a delicate balance between high metabolic requirements and oxidative damage. Adv. Exp. Med. Biol. 949, 167-181. doi: 10.1007/978-3-319-40764-7_8

Saroff, D., Delfs, J., Kuznetsov, D., and Geula, C. (2000). Selective vulnerability of spinal cord motor neurons to non-NMDA toxicity. Neuroreport 11, 1117-1121. doi: 10.1097/00001756-200004070-00041

Sattler, R., Tymianski, M., Feyaz, I., Hafner, M., and Tator, C. H. (1996). Voltagesensitive calcium channels mediate calcium entry into cultured mammalian sympathetic neurons following neurite transection. Brain Res. 719, 239-246. doi: 10.1016/0006-8993(96)00125-4

Savigni, D. L., O’Hare Doig, R. L., Szymanski, C. R., Bartlett, C. A., Lozic, I., Smith, N. M., et al. (2013). Three $\mathrm{Ca}^{2+}$ channel inhibitors in combination limit chronic secondary degeneration following neurotrauma. Neuropharmacology 75, 380-390. doi: 10.1016/j.neuropharm.2013.07.034

Schindelin, J., Arganda-Carreras, I., Frise, E., Kaynig, V., Longair, M., Pietzsch, T., et al. (2012). Fiji: an open-source platform for biological-image analysis. Nat. Methods 9, 676-682. doi: 10.1038/nmeth.2019

Sim, F. J., Zhao, C., Penderis, J., and Franklin, R. J. M. (2002). The age-related decrease in CNS remyelination efficiency is attributable to an impairment of both oligodendrocyte progenitor recruitment and differentiation. J. Neurosci. 22, 2451-2459. doi: 10.1523/JNEUROSCI.22-07-02451.2002

Smith, R. R., Burke, D. A., Baldini, A. D., Shum-Siu, A., Baltzley, R., Bunger, M., et al. (2006). The Louisville Swim Scale: a novel assessment of hindlimb function following spinal cord injury in adult rats. J. Neurotrauma 23, 1654-1670. doi: 10.1089/neu.2006.23.1654

Springer, J. E., Azbill, R. D., Mark, R. J., Begley, J. G., Waeg, G., and Mattson, M. P. (1997). 4-hydroxynonenal, a lipid peroxidation product, rapidly accumulates following traumatic spinal cord injury and inhibits glutamate uptake. J. Neurochem. 68, 2469-2476. doi: 10.1046/j.1471-4159.1997.680 62469.x

Stys, P. K. (2004). White matter injury mechanisms. Curr. Mol. Med. 4, 113-130. doi: $10.2174 / 1566524043479220$

Szydlowska, K., and Tymianski, M. (2010). Calcium, ischemia and excitotoxicity. Cell Calcium 47, 122-129. doi: 10.1016/j.ceca.2010.01.003

Szymanski, C. R., Chiha, W., Morellini, N., Cummins, N., Bartlett, C. A., O'Hare Doig, R. L., et al. (2013). Paranode abnormalities and oxidative stress in optic nerve vulnerable to secondary degeneration: modulation by $670 \mathrm{~nm}$ light treatment. PLoS One 8:e66448. doi: 10.1371/journal.pone. 0066448
Tamaki, Y., Araie, M., Fukaya, Y., Nagahara, M., Imamura, A., Honda, M., et al. (2003). Effects of lomerizine, a calcium channel antagonist, on retinal and optic nerve head circulation in rabbits and humans. Invest. Ophthalmol. Vis. Sci. 44, 4864-4871. doi: 10.1167/iovs.02-1173

Thorburne, S. K., and Juurlink, B. H. J. (1996). Low glutathione and high iron govern the susceptibility of oligodendroglial precursors to oxidative stress. J. Neurochem. 67, 1014-1022. doi: 10.1046/j.1471-4159.1996.67031014.x

Toomey, L. M., Bartlett, C. A., Majimbi, M., Gopalasingam, G., Rodger, J., and Fitzgerald, M. (2019). Comparison of ion channel inhibitor combinations for limiting secondary degeneration following partial optic nerve transection. Exp. Brain Res. 237, 161-171. doi: 10.1007/s00221-018-5414-0

Totoiu, M. O., and Keirstead, H. S. (2005). Spinal cord injury is accompanied by chronic progressive demyelination. J. Comp. Neurol. 486, 373-383. doi: $10.1002 /$ cne.20517

Tsutsui, S., and Stys, P. K. (2013). Metabolic injury to axons and myelin. Exp. Neurol. 246, 26-34. doi: 10.1016/j.expneurol.2012.04.016

Tuszynski, M. H. (2005). New strategies for CNS repair. Ernst Schering Res. Found. Workshop doi: 10.1007/3-540-27626-2_1 [Epub ahead of print].

Vaishnav, R. A., Singh, I. N., Miller, D. M., and Hall, E. D. (2010). Lipid peroxidation-derived reactive aldehydes directly and differentially impair spinal cord and brain mitochondrial function. J. Neurotrauma 27, 1311-1320. doi: 10.1089/neu.2009.1172

Van Den Bosch, L., Vandenberghe, W., Klaassen, H., Van Houtte, E., and Robberecht, W. (2000). $\mathrm{Ca}^{2+}$-permeable AMPA receptors and selective vulnerability of motor neurons. J. Neurol. Sci. 180, 29-34. doi: 10.1016/s0022$510 x(00) 00414-7$

Wang, X., and Michaelis, E. K. (2010). Selective neuronal vulnerability to oxidative stress in the brain. Front. Aging Neurosci. 2:12. doi: 10.3389/fnagi.2010.00012

Warden, P., Bamber, N. I., Li, H., Esposito, A., Ahmad, K. A., Hsu, C. Y., et al. (2001). Delayed glial cell death following Wallerian degeneration in white matter tracts after spinal cord dorsal column cordotomy in adult rats. Exp. Neurol. 168, 213-224. doi: 10.1006/exnr.2000.7622

White, N.-H., and Black, N.-H. (2016). National Spinal Cord Injury Statistical Center, Facts and Figures at a Glance. Birmingham, AL: University of Alabama at Birmingham, 2020.

Wiesenfeld-Hallin, Z., Hökfelt, T., Lundberg, J., Forssmann, W., Reinecke, M., Tschopp, F., et al. (1984). Immunoreactive calcitonin gene-related peptide and substance $\mathrm{P}$ coexist in sensory neurons to the spinal cord and interact in spinal behavioral responses of the rat. Neurosci. Lett. 52, 199-204. doi: 10.1016/03043940(84)90374-4

Yates, N. J., Giacci, M. K., O'Hare Doig, R. L., Chiha, W., Ashworth, B. E., Kenna, J., et al. (2017). Delayed treatment of secondary degeneration following acute optic nerve transection using a combination of ion channel inhibitors. Neural Regen. Res. 12, 307-316. doi: 10.4103/1673-5374. 200814

Conflict of Interest: The authors declare that the research was conducted in the absence of any commercial or financial relationships that could be construed as a potential conflict of interest.

Copyright (๑ 2020 O'Hare Doig, Santhakumar, Fehily, Raja, Solomon, Bartlett, Fitzgerald and Hodgetts. This is an open-access article distributed under the terms of the Creative Commons Attribution License (CC BY). The use, distribution or reproduction in other forums is permitted, provided the original author(s) and the copyright owner(s) are credited and that the original publication in this journal is cited, in accordance with accepted academic practice. No use, distribution or reproduction is permitted which does not comply with these terms. 